STATUS AND PLANS

OF

THE DEPARTMENT OF THE INTERIOR

EROS PROGRAM

U. S. Geolog1cal Survey

OPEN FILE REPORT

75-376

July 1975 
Property of:

Don Kulow Library

EROS Data Center

Sioux Falls, SD 57198

\section{STATUS AND PLANS}

OF

THE DEPARTMENT OF THE INTERIOR

EROS PROGRAM

Property of:

Don Kulow Library

EROS Data Center

Sioux Falls, SD 57198

U. S. Geologicas survey

OPEN FILE REPORT

75-376

July 1975 

List of Illustrations . . . . . . . . . . . . . . iii List of Tables . . . . . . . . . . . . . . . . v v

Abstract . . . . . . . . . . . . . . . . 1

Introduction . . . . . . . . . . . . . . . 3

EROS Program ...................... 5

Near Term LANDSAT Processing Requirements . . . . . . . 13

Current LANDSAT Applications Demonstrations . . . . . . . 16

Energy and Minerals ............... 16

Monitoring and Planning ............ 22

Image Maps . . . . . . . . . . . . . 46

Products from Digital Analysis ............ 52

Data Collection Platforms ........... 59

Longer Term Research . . . . . . . . . . . . . 64

Precision Measurements of Intercontinental Distance . . 65

Global Measurements of the Earth's Magnetic Field . . . 66

Shallow Seas Mapping by Passive Remote Sensing . . . 69

Luminescence Studies . . . . . . . . . . 70

Satellite Thermography . . . . . . . . . . 72

Microwave Studies of Natural Materials . . . . . . 76

Summary . . . . . . . . . . . . . . . 79

References .................... 82 

Fig. 1 LANDSAT-1 image of the Chagai region in Pakistan.

Fig. 2 LANDSAT-1 images of the San Francisco Bay area.

Fig. 3 LANDSAT-1 images of part of Holt County, Nebraska.

Fig. 4 Geologic map of the Duncan Flats Quadrangle.

Fig. 5 Strip mine map of the Duncan Flats Quadrangle showing areal extent of strip mines.

Fig. 6 IANDSAT image mosafc of Iceland.

Fig. 7 Probably oil slick detected by LANDSAT-1.

Fig. 8 LANDSAT-1 image mosaic showing areal extent of

flood of the Mississippi River (Spring, 1973)

between St. Louis, Missouri, and the Gulf of Mexico.

Fig. 9 Enhanced LANDSAT-1 images of the Pakistan Flood.

Fig. 10 Enlarged LANDSAT-MSS image showing the Dismal Swamp. 39

Fig. 11 LANDSAT (ERTS) data guides development of Florida's 40 Green Swamp area.

Fig. 12 Map prepared from IANDSAT imagery by Bangladesh 42 scientists showing accretion of new land at the mouth of the Ganges River. 
Fig. 13 Satellite image map of Arizona showing highways.

Fig. 14 Satellite image map of Arizona showing remote subdivisions.

Fig. 15 Land use map of Washington, D. C., at the time of the 1970 census.

Fig. 16 Land use map of Washington, D. C., prepared from LANDSAT imagery acquired in April and October 1973.

Fig. 17 Data collection platform field layout and communication links, Project Skywater, Custer County, Montana.

Fig. 18 Satellite magnetic map of Africa.

Fig. 19 Curves showing duirnal variation in the luminescence intensity of Pinus ponderosa.

Fig. 20 NOAA Very High Resolution Radiometer (VHRR) image (visible light) of Iceland and Greenland.

Fig. 21 NOAA Very High Resolution Radiometer (VHRR) image (infrared) of Iceland and Greenland. 
$\underline{\text { Page }}$

Table 1. Income from various data products produced by the EROS Data Center during fiscal years 1973-1975. . . . . . . . . . 6

Tab1e 2. Summary of disaster applications of an operational LANDSAT . . . . . . . . . 45 

The Earth Resources Observation Systems (EROS) Program of the Department of the Interior has been actively participating in the LANDSAT (formerly ERTS) program and other investigations with remotely sensed data. A large number of applications have been demonstrated that can assist in the discovery of nonrenewable resources, monitoring areal extent of renewable resources, monitoring environmental change, and in providing repetitive data for planimetric revision of small-scale maps and maps showing land cover classes. A new and potentially revolutionary approach, that of "automated cartography," has been initiated through the versatile nature of the data available from LANDSAT. "Automated cartography" as used here refers to the ability to automatically extract land cover classes and relate these classes to geographic position.

Providing high-quality data in a timely manner to users is an area where some progress has been made, but additional improvements are needed. The technical solutions to these problems are known, but the ability to speedily implement these solutions will depend on the levels of support available to the program.

Technology transfer to make the methods of using LANDSAT data available to organizations with resource management responsibilities is in progress. The primary steps being taken by the EROS Program are training courses, workshops, documentation of analysis methods and, where necessary, direct support of relevant research. 
LANDSAT data and other types of space-acquired data provide a powerful mechanism for both interdisciplinary scientific exchange and international scientific cooperation. The current program and the envisioned future Earth-related uses of acquired data offer the potential for an increase in this type of objective exchange as well as enable us to better understand our global environment, to search for and locate nonrenewable resources, monitor our use of renewable resources, and to make the necessary decisions to protect the environment upon which we all depend.

It is worth recognizing and remembering that LANDSAT is only a beginning. Some would say a revolutionary one, but still only a start in putting space technology into the service of all mankind. 
The U. S. Department of the Interior Earth Resources Observation Systems (EROS) Program was established in 1966 by Secretarial order. This program is dedicated to planning and developing remote sensing data gathering and analysis techniques and applying them to the resource and environmental inventory and management responsibilities of the Department of the Interior. This is done in cooperation with the National Aeronautics and Space Administration (NASA) and other agencies. It is appropriate that progress that has been made be documented and future needs considered at this time. A report entitled, "Scope, importance and resolution requirements of geoscience problems to be attacked by orbital remote-sensor measurements," was issued 10 years ago (U. S. Geo1. Survey, 1965). The report has been referred to as "The Scope Document" and it provided the basic scientific guidelines for formation of the EROS Program. It also aided in establishing the Department of the Interior requirements for satellite data which helped in determining the basic design of the ERTS (now LANDSAT) system. The intent of the present report is to review the status and plans of the EROS Program based on the experience of the past ten years and provide an outlook into future directions of research.

Many of the basic requirements for space-acquired data outlined in "The Scope Document" have already been met. Oux ability to obtain many of the remaining benefits will require only modest augmentation to our current program. It is surprising even to those who have been 
deeply involved in the program since its inception, how well the initial LANDSAT system has performed and how extensive the variety of user applications has been. While this report attempts to summarize some of the more significant results of research and applications demonstration projects, U. S. Geological Survey Professional Paper 929 (Williams and Carter, in press) contains 85 case histories on the applications of ERTS-1 (LANDSAT-1) data to global cartographic, geologic, hydrologic, geographic, and oceanographic problems. This professional paper serves as a major bench mark in the substantive documentation of the applications of Earth satellite remote sensing systems for operational programs.

The final section of this report considers long-term research that will form the elements for new capabilities which will enable us to better understand the world in which we live, to use the resources available to us, and to protect the environment on which we depend. The proposed research objectives could be accomplished in 5 to 10 years if national priorities and adequate funding could be dedicated to such efforts.

Other nations of the world, especially those in less developed regions or those which encompass large areas, have quickly recognized the need for information derived from space in a repetitive and timely manner. Dr. Fernando Mendonca, Director of the Brazilian space agency (INPE), has stated that "Space technology is a better form of aid than dollars." Five foreign countries have a total of six LANDSAT reception stations either operating or to begin operating in the next year. An additional five countries are considering the construction of LANDSAT reception stations at this time. 
The purpose of the EROS Program is to develop, demonstrate, and encourage applications of remote-sensing data acquired from aircraft and spacecraft which are relevant to functional responsibilities of the Department of the Interior. The Department's responsibilities include topographic mapping, mineral, water, and land resource inventories, and management of Federal and Indian lands, national parks, recreational areas, and wildlife refuges.

The EROS Program is administered for the department by the Geological Survey. Program personnel work with representatives of departmental bureaus and offices to coordinate and jointly sponsor applications of remote-sensing technology to activities of the department. Much of the research, which has resulted in the demonstration of many applications, has been made possible by the experimental data acquisition systems of NASA, such as LANDSAT-1 and -2 and Skylab, as well as the aerial remote sensing research program. Other research draws from other data collection systems, such as the National Oceanic and Atmospheric Administration (NOAA) weather satellites, and aircraft remote-sensing capabilities sponsored by other Federal and State agencies.

The EROS Program Office is located in Reston, Virginia. In addition to activities within the department, this office maintains close contact with NASA headquarters, NASA field centers, NOAA, 
U. S. Department of Agriculture, and U. S. Army Corps of Engineers, as well as participating State agencies. The office coordinates research activities, directs data reproduction and distribution, training programs, and supports applications assistance facilities and browse files throughout the country.

A major element of the program is the EROS Data Center (EDC) at Sioux Falls, South Dakota. Data archived at the center total approximately 6,000,000 images, including over 500,000 frames of LANDSAT imagery; LANDSAT electronic data in the form of computer compatible tapes; over 40,000 frames of Skylab, Apollo, and Gemini data; more than $1,800,000$ frames of data from the NASA Research Aircraft Program; and almost 4,000,000 frames of Department of the Interior aerial mapping photography.

The demand for reproduction of these archived data has continued to increase both in number of frames and dollar value. In FY 73, 165,000 frames of data were supplied to the user community, data for whom grew to almost 300,000 frames in FY 74, and has exceeded 400,000 frames in FY 75. At the same time, dollar income at the center increased by 91 percent from FY 74 to FY 75, with total dollar income from the sale of data exceeding $\$ 1.6$ million in FY 75 (table 1 ).

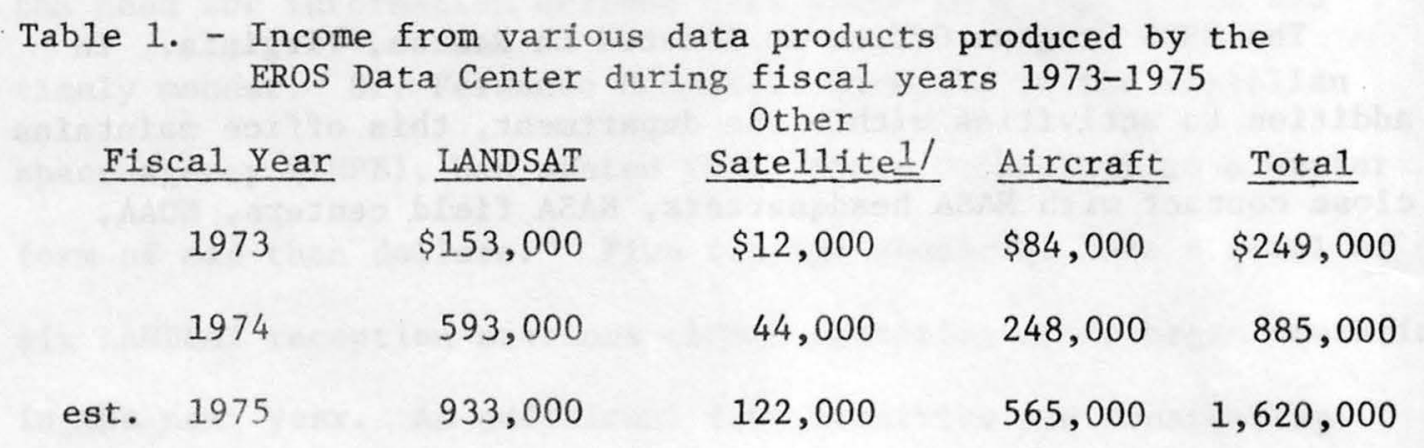

If Gemini, Apollo, and Skylab imagery and photography 
Approximately 58 percent of the dollar value for products at the center is for LANDSAT data. The customer profile for purchase of all data shows that private industry is the largest single purchaser, with 30 percent of the total dollar value, and agencies of the Federal Government coming next with 24 percent. Academic and educational institutions account for 16 percent of data sales, while foreign customers comprise 12 percent. Individuals, State, and local government agencies comprise the remainder.

A look at the principal users and purchases of EDC products reveals that almost all categories of U. S. industry and a wide variety of Federal, State, and local government agencies are using the data for a multitude of applications. The principal application of the data is in mineral and petroleum exploration and related geologic base mapping activities of the major petroleum and mining companies.

An analysis of energy-related purchases of data from the EROS Data Center has recently been completed. The results indicate that from a Forbes list of 500 U. S. Industries, 113 are energy related, and 81 of these have purchased data from the EROS Data Center. Thirty-four of the 81 energy-related industries show a highly repetitive ordering pattern, eithei initiating new orders on approximately a monthly basis, or retaining standing orders for data as they become available. This degree of interest and data utilization is a strong indication of the contribution the program is making to assist industry in finding solutions to our national energy and mineral resource problems. 
To facilitate regional applications, the EROS Program operates seven Applications Assistance Facilities where the public may view microfilm copies of imagery available from the Data Center and may receive assistance in searching and ordering data via computer terminal inquiry and order capability to the central computer complex at the EROS Data Center. These facilities also offer assistance in techniques of applying the data to resource problems. Facilities are currently established in Menlo Park, California; Phoenix, Arizona; Denver, Colorado; Reston, Virginia; Bay St. Louis, Mississippi; Ft. Clayton, Canal Zone; and Fairbanks, Alaska. In addition to these offices, 11 Data Reference Files have been established throughout the United States to maintain microfilm copies of the most used data available from the center and to provide assistance to the visitor in reviewing and ordering data.

A new Burroughs B6700 General Purpose Computer System is scheduled for installation at EDC in August 1975, that will accommodate the increased data demand projected in FY 76 by allowing improved data base control and accession, data production scheduling and control, data processing and analysis, automated accounting and business systems, and increased capacity for remote terminals interfacing with the data base.

The principal role of the EROS Data Center in applications assistance is technology transfer. Technical training and assistance programs for use and application of remotely sensed Earth resources data continues to increase at the data center. Normally, these training programs are up to 1 week in length and stress the use of 
data in a particular application, for example, agricultural and forest inventory, wildlife and water management, and mineral exploration. Supplementing these formal training courses are a series of slide tape packages and educational aids covering the basic methodology in remote sensing and various applications.

During 1974 and 1975 workshops of 3- to 4-day duration were conducted for personnel from the Bureau of Mines and the Fish and Wildlife Service of the Department of the Interior. Additional workshops have been conducted for the South Dakota State Planners; the North Dakota Water Commission; the Bureau of Land Management of the Department of the Interior; the Animal Plant Health Inspection. Service, Forest Service, and Statistical Reporting Service of the Department of Agriculture; and the Pacific Northwest Regional Commission. Workshops planned for the near future include the Soil Conservation Service of the Department of Agriculture, Bureau of Land Management, Fish and Wildlife Service, and the Bureau of Reclamation. Other workshops in the planning stages include multidisciplinary uses of LANDSAT data and geologic analysis for mineral and petroleum exploration.

Scientists from the EROS Data Center are assisting Federal, State and local government agencies in determining the utility of remote-sensing data for a number of applications including: Land use analysis of South Dakota, land cover mapping of the Pacific Northwest (Washington, Oregon, and Idaho), forest defoliation mapping and damage assessment, and sampling strategy design for agricultural 
inventory. In addition, elements of the Department of Agriculture and NOAA are using the advanced digital classification capabilities available at the center.

Two or three times a year, a 3- to 4-week course is offered to foreign nationals, stressing the fundamentals of remote sensing with emphasis on specific applications. To date there have been 102 attendees from 39 countries. Ten African countries, 15 Asian countries, 6 European countries, 7 South American countries, and Australia have been represented. The four courses that have been conducted were in June 1973, June 1974, September 1974, and May 1975. An additional course is planned for September 1975.

Training in foreign countries consisting of lectures, workshops, and seminars have been conducted by EROS Program personnel at no travel cost to the department. This is indicative of the international need and interest in remote-sensing training. Countries visited during FY 75 included Australia, Algeria, Thailand, Costa Rica, Venezuela, Mali, Mexico, and Ghana. Sources of funding have been the Governments of Australia, Algeria, and Mexico, and Economic and Social Commission for Asia and the Pacific of the United Nations (ESCAP) U. S. Information Agency (USIA), and U. S. Agency for International Development (USAID).

A cooperative program was initiated between the EROS Program and the Defense Mapping Agency in June 1971. The Defense Mapping Agency used its Inter American Geodetic Survey offices in Fort Clayton, Canal Zone, as a central dissemination point for LANDSAT and Skylab 
data to cooperating Latin American countries. Seminars and training courses were conducted in Spanish at Fort Clayton. Over 130 participants from 16 countries have received training under this program. This activity has resulted in the use of LANDSAT data by Latin American mapping agencies. Under this program, browse files and data centers have been established in the mapping agencies of 16 Central and South American countries. Most of these centers indicate increasing use by interested local nationals as they learn more about the availability of satellite data. User groups include national resource agencies, universities, and commercial mineral and energy resource companies.

Increased interest in the use of LANDSAT data collection platforms (DCP) and relay capability for monitoring remote regions has developed in Latin America. USAID sponsored a special 2-week seminar on DCP technology held in Brazil in November 1974, and the EROS Program supported similar lectures in Chile, Bolivia, and Peru. The University of Chile and the NASA tracking station at Colinas are now considering increasing their capability to receive relayed DCP data directly for South America. The EROS Program and Inter American Geodetic Survey sponsored a 1-week workshop at Fort Clayton, Canal Zone, for 30 Latin Americans from nations interested in data relay techniques in June 1975.

In the future, the EROS Data Center will emphasize applications assistance activities and continue to cooperate with NASA in supplying satellite imagery and electronic products in the shortest possible time period and in flexible user-required formats. The Goddard Space Flight Center has implemented increased computer 
compatible tape production capability for LANDSAT-2, and the EROS Data Center is making changes to handle this increase and to provide more flexible format for computer compatible tape reproduction and dissemination to users. For LANDSAT-C, now scheduled for launch in late 1977, NASA and the Department of the Interior are studying concepts for the use of communication satellites for relaying image data to significantly improve the timeliness of data dissemination. This concept includes the reception of data at the NASA Alaska, Goldstone, and Goddard reception stations, with subsequent relay to Sioux Falls on a near-real time basis for further processing, reproduction, and dissemination to users.

In addition, conceptual studies and plans are underway on how to more efficiently handle data from LANDSAT-C and subsequent satellites. NASA plans to use high-density tape formats which should then be integrated with high-density tape at the EROS Data Center to provide improved products, including imagery and computer compatible tapes, to users in a much more timely and efficient fashion. The ultimate goal is to provide data to the users in the unique formats required and with maximum information content in 24 to 48 hours of satellite acquisition. 
Current production-line image duplication of LANDSAT data is done by all-film systems which are unable to provide all of the initial information acquired by the satellite. This loss of data can be overcome by implementation of a digital data handling and processing capability at the EROS Data Center which would include the software and hardware to provide radiometrically and geometrically corrected digital and photographic products from high-density digital tapes. The advantages would be:

a. Users could be provided with a first-generation image produced from a tape archive, instead of a radiometrically inferior fourth-generation image produced from a film archive.

b. Magnetic tape recordings of LANDSAT data retain four times the dynamic range available on the present film products. Film products made directly from a tape archive can be modified routinely in accordance with a user's specific needs; for example, spectral detail in water, vegetated, urban, or bedrock areas could be selectively displayed and enhanced on single or composited images. Procedures for performing this function now are expensive, awkward, and limited in availability.

c. Geometric rectification, in accordance with standard cartographic projections, could be achieved routinely without loss of either spatial or spectral resolution. 
Only two or three organizations in the U. S. have demonstrated this capability in research projects; the service is not routinely available and is expensive. Costs could be greatly reduced if this service were supplied in the production facility.

Surface shipment of LANDSAT data from reception stations to Goddard, and transshipment to EDC requires a minimum of 3 weeks. This delay precludes uses of data in rapid management decisions. Implementation of a LANDSAT data "quick-1ook" capability at EDC would provide image data to users in $24-48$ hours.

Data distribution to users subscribing to a "quick-1ook" service would be by mail or by photo facsimile depending on the user requirement and the communication technology adopted.

Research has shown that applications requiring rapid delivery may include the following:

a. Direct observation of change in areal extent of snow in order to improve estimates of snowpack and timely prediction of runoff in hydroelectric and irrigation catchment basins.

b. Rapid identification and mapping of the areal extent of floods.

c. Rapid regional assessment of range grass condition to guide release or withdrawal of grazing leases.

d. Monitoring surface water change in large stock ponds and/or range reservoirs to guide release or withdrawal of grazing leases.

e. Timely crop inventory to supplement slower conventional crop reporting activities. 
f. Rapid assessment of change in cropland vigor due to floods, hail, wind, temperature, drought, and crop disease.

g. Direct observation of the seasonal variations of nearshore coastal currents, as manifested by suspended material in the water, in order to help predict on-shore damage by oil spills and other toxic materials.

h. Direct observation of oil spills. Oil on the sea exhibits spectral contrast with a water background, particularly in the red and near-infrared bands of LANDSAT. This is due to a combination of factors, including optical properties of the oil and damping of capillary waves on the ocean surface by the oil.

The need for "quick-1ook" products is we11 recognized abroad; six foreign-owned LANDSAT reception stations in five countries, how operational or planned, include "quick-1ook" facilities. Major use of the Canadian "quick-1ook" products is for marine navigation through the Canadian archipelago and related energy development activities in the MacKenzie delta area. A U. S. "quick-1ook" capability would permit similar uses in the Alaskan Arctic region which is beyond the range of the Canadian station. 
The following section contains examples of progress that has been made in the use of remote-sensing data and, where applicable, shows how the derived information is being used in making decisions.

\section{Energy and Minerals}

Representatives from a number of petroleum and petroleum exploration companies attended a meeting held at the University of Kansas in February 1975. Both in presented papers and in private discussions, it became apparent that the petroleum industry is not only the largest single customer of data from LANDSAT, but that they are now using the data routinely to improve their total exploration and planning programs.

One company representative stated that LANDSAT data have saved his company at least $\$ 1,000,000$ on studies of leases in Tunisia, Egypt, Yemen, and Sumatra during the past year. The characteristics of broad overview and low sun angle perspective provided by LANDSAT images have enabled his company to select targets for detailed geological and geophysical exploration. Another representative stated that LANDSAT images of the United States are being used extensively; LANDSAT is providing new structural information that will extend known and producing oilfields in the United States. Another representative has been analyzing the photo mosaic of the United States that was prepared by the U. S. Department of Agriculture's Soil Conservation Service. He believes that he has 
defined fundamental crustal structures that may require modification of current theories of crustal deformation.

A paper presented at the Kansas meeting by John B. Miller of Chevron Overseas Petroleum, Inc., demonstrated how LANDSAT data have assisted in exploration in Kenya. He states that "ERTS (LANDSAT) studies have the advantage of very quick interpretation over new areas and regions. Such work saves time and money and gives a substantial basis for new ideas."

In Alaska, landform analysis of LANDSAT-1 images, substantiated by geophysical data, persuaded Fischer and Lathram (1973) to propose a new area for petroleum exploration. As seen on the images, lakes in the Arctic Coastal plain are dominantly elongate, having their long axes parallel and trending about N. $9^{\circ} \mathrm{W}$. Northwest of the Umiat oil field, an additional strong east-trending regional. lineation not previously recognized on aerial photographs or in field study, is expressed by elongation of some lakes, alinement of others, and by linear interlake areas. The trend of this lineation is parallel to the trend of deflections in contours of the magnetic and gravity fields in the area and parallel to westerly deflections in the northwest ends of northwest-trending folds mapped to the south. In addition, the alinement of many small lakes forms a large ellipse superimposed on the regional lineation. Sparse seismic profiles show periodic reversals in dip and regional arching in shallow strata beneath the lineated area. Collectively, these data suggest that heretofore unsuspected deep structures may be concealed beneath the younger Quaternary Gubik Formation that covers the area of the image. In addition, strata in shallow folds are younger than those tapped 
by the oil wells of the Umiat field to the south, and may contain favorable reservoir beds.

Mosaics of the conterminous United States compiled by the Soil Conservation Service for NASA have been analyzed by U. S. Geological Survey geologists interested in linear features that may be of tectonic significance. Mosaics at scales of $1: 5,000,000$ and $1: 1,000,000$ were used to evaluate and identify new and to re-evaluate previously known geologic features. Studies of smaller regions have shown that the occurrence of major mineral deposits are closely related to the intersection of linear features that are major fracture systems. Similar studies of gas-producing areas in the Appalachians show that the most productive gas wells are near or within areas of highly fractured bedrock. Recent petroleum discoveries in the Mobile Bay region of Alabama are consistent with interpretations of linears on LANDSAT images.

Rowan and others (1974) provide a detailed description of the development and application of a new remote-sensing technique for geologic exploration. A combination of digital computer processing and color compositing of LANDSAT Multispectral Scanner (MSS) images was used to detect and map hydrothermally altered areas associated with ore deposits and to discriminace most major rock types in south-central Nevada. MSS spectral bands were combined by ratioing techniques, picture element by picture element, and were subsequently enhanced by "contrast stretching" to magnify subtle spectral differences. The technique used in the study appears to have important applications in mineral-resources exploration and regional geologic 
mapping by rapidly extending geologic information from well-known regions to lesser known areas on the basis of spectral reflectance characteristics. There is a probability, therefore, of shortening the time between exploration for and discovery of economic mineral deposits and their ultimate development and industrial use.

In an investigation that was recently completed in the Nabesna quadrangle in east-central Alaska, large linear features that are too long to be recognized on conventional aerial photographs have been correlated with known mineral deposits (Albert, 1975; Richter and others, 1975). The computer techniques for enhancement of the images used led to tentative conclusions that 56 percent of all known metallic mineral occurrences in this quadrangle lie within approximately 1 mile of the LANDSAT-identified linear features. Color anomalies on the computer-enhanced LANDSAT imagery account for 72 percent of these known mineral occurrences. Some of the observed color anomalies coincide with areas of known geochemical alteration and some of the remaining anomalies constitute "resource targets."

Schmidt (1975) used enhanced LANDSAT imagery to examine the characteristics of known copper deposits in Pakistan. Figure 1 shows this imagery and the area of the known copper deposits. He then examined the imagery to find areas that have similar spectral and textural characteristics. He found 19 areas that he considered to be potential sites for the presence of mineralized rock. Of these, he was able to confirm surface mineralization by field inspection at five of the locations. 


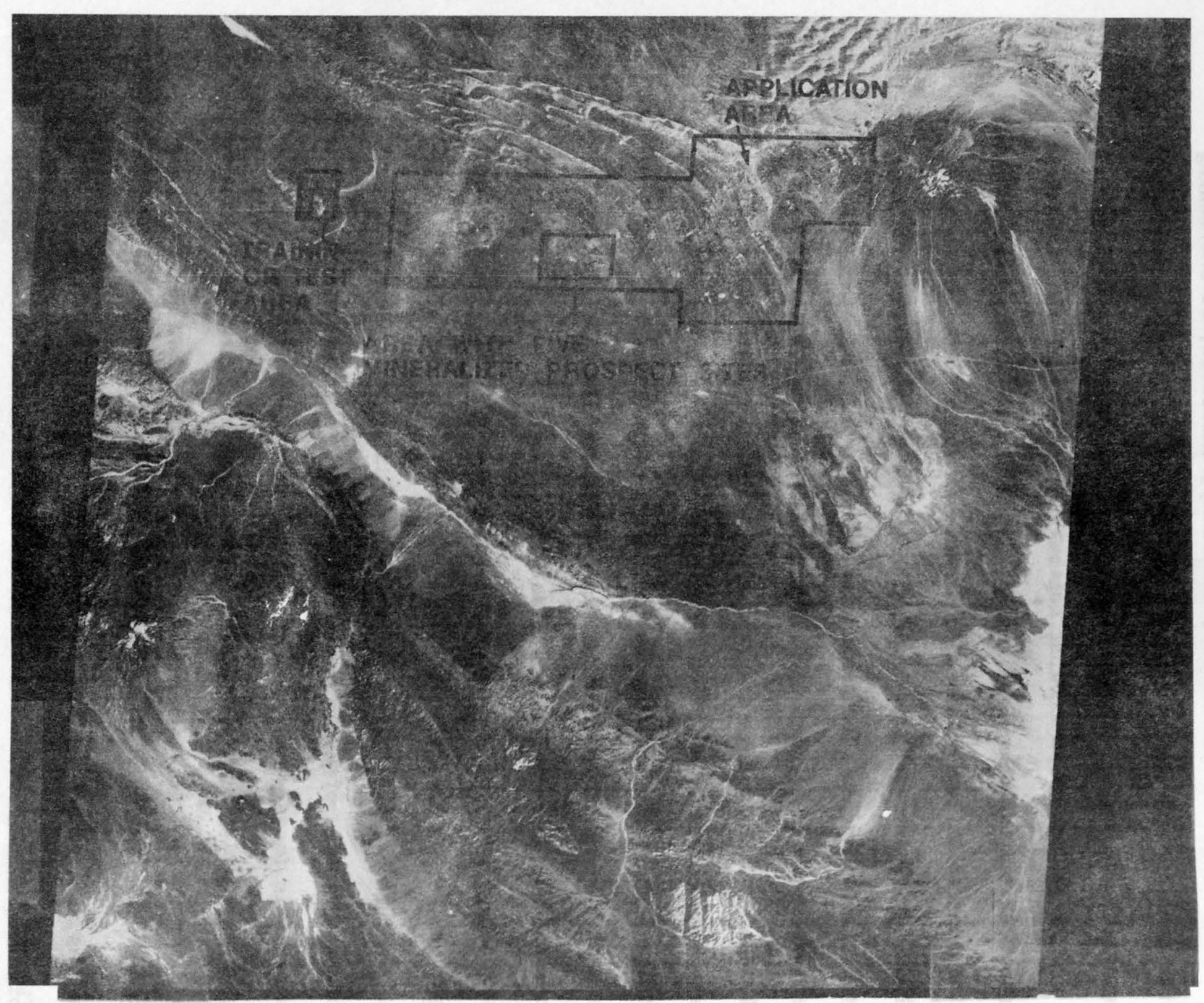

Fig. 1 - LANDSAT-1 image of the Chagai region in Pakistan showing the training or test area where copper mineralization is known, and the application area where 19 potential sites of copper mineralization were delineated. Field study verified surface mineralization at 5 of the 19 sites. (Color composite LANDSAT image 1125-05545) 
A LANDSAT experiment conducted jointly by the U. S. Geological Survey and the Geological Surveys of Venezuela, Colombia, Peru, Chile, Bolivia, Argentina, and Brazil, has been underway since 1973 (W. D. Carter, 1974, 1975). Mosaics covering more than 1 million $\mathrm{km}^{2}$ have been constructed for selected portions of the Andes Mountains. Linear features identified on the mosaics have been compared to maps showing distribution of known ore deposits in order to define areas favorable for exploration. One copper deposit of potential value has been found in Bolivia. The maps showing linear features have also been compared with earthquake records to show areas of high seismic risk.

Recent efforts in the Andes have been aimed at evaluating the reflectance characteristics of various types of rocks, which serve as host rocks of ore deposits, by using computer recognition techniques. Initial results indicate that LANDSAT data and interactive computer systems can be used to correlate rock types over broad regions and between countries where the degree of field mapping may vary considerably according to relative accessibility. 
Repetitive and timely images from satellite platforms can permit agencies having information gathering and management responsibilities to conduct their missions in a more rapid and efficient manner. Most of the agencies within the Department of the Interior have missions of this type. For example, the Bureau of Land Management is responsible for managing over 451 million acres of forest and range lands in the western United States and Alaska. Land use decisions must be reached quickly to meet the greatest public need. Rangeland must be monitored and managed so that forage is not overgrazed and yet is productive.

The Bureau of Land Management and EROS have sponsored a pilot study in rangeland monitoring in the Susanville district of California. The study, conducted by the University of California, Berkeley, was directed at a large variety of problems that are of concern to the bureau, and the results are to be made widely available within the bureau, so that applicable portions can be utilized operationally in the various regions. Specific demonstrations from this study include the ability to make rapid regional assessments of range class conditions to guide release or withdrawal of grazing leases (fig. 2). It is also possible to monitor surface-water changes in large stock ponds and range reservoirs to guide decisions concerning grazing leases. Rapid changes in range conditions can occur as a result of floods, hail, wind, temperature, drought, and disease. Effect of all of these factors on range condition can be 


\section{APRIL SCENE}

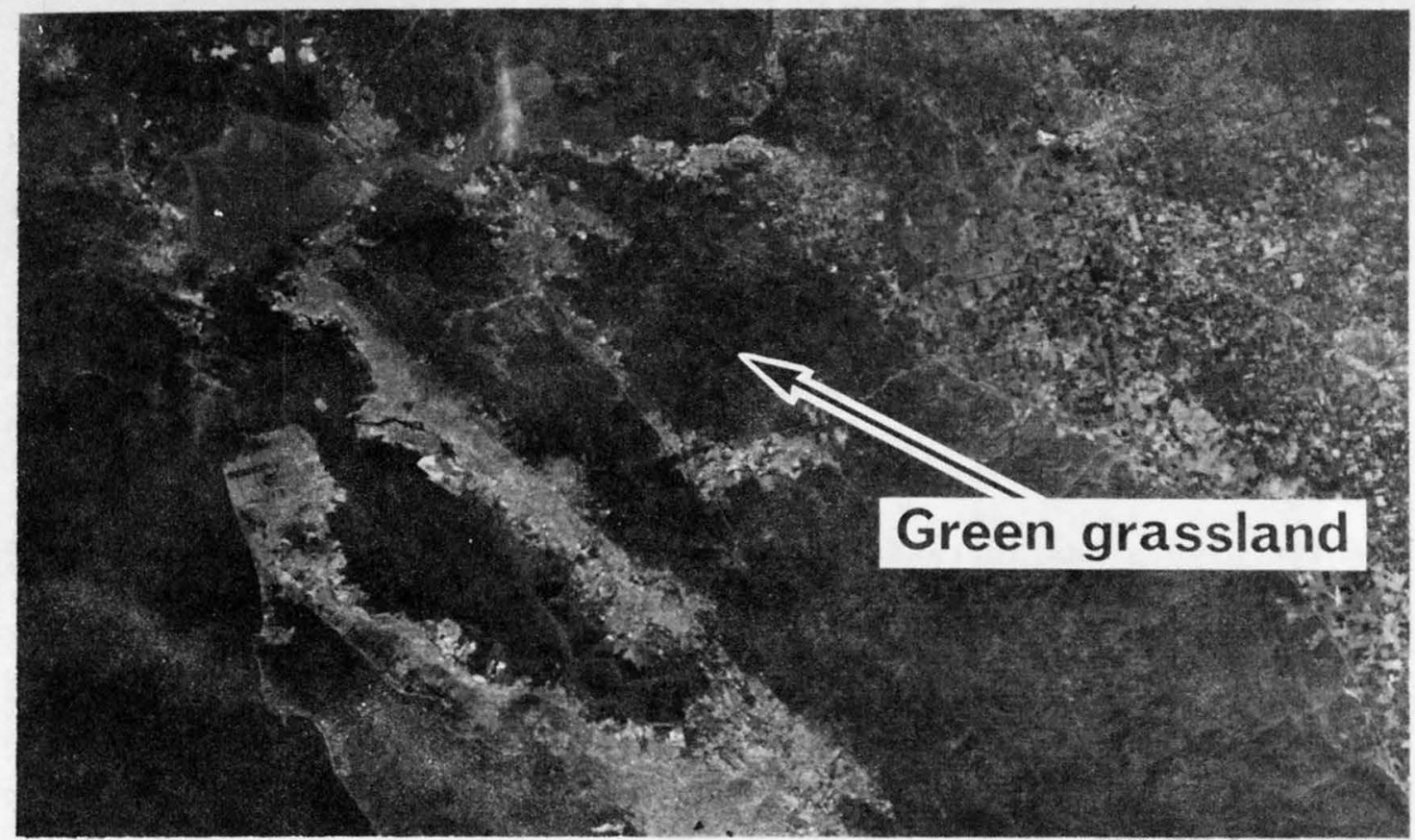

22APR73

NASA ERTS E-1273-18183-5

\section{JUNE SCENE}

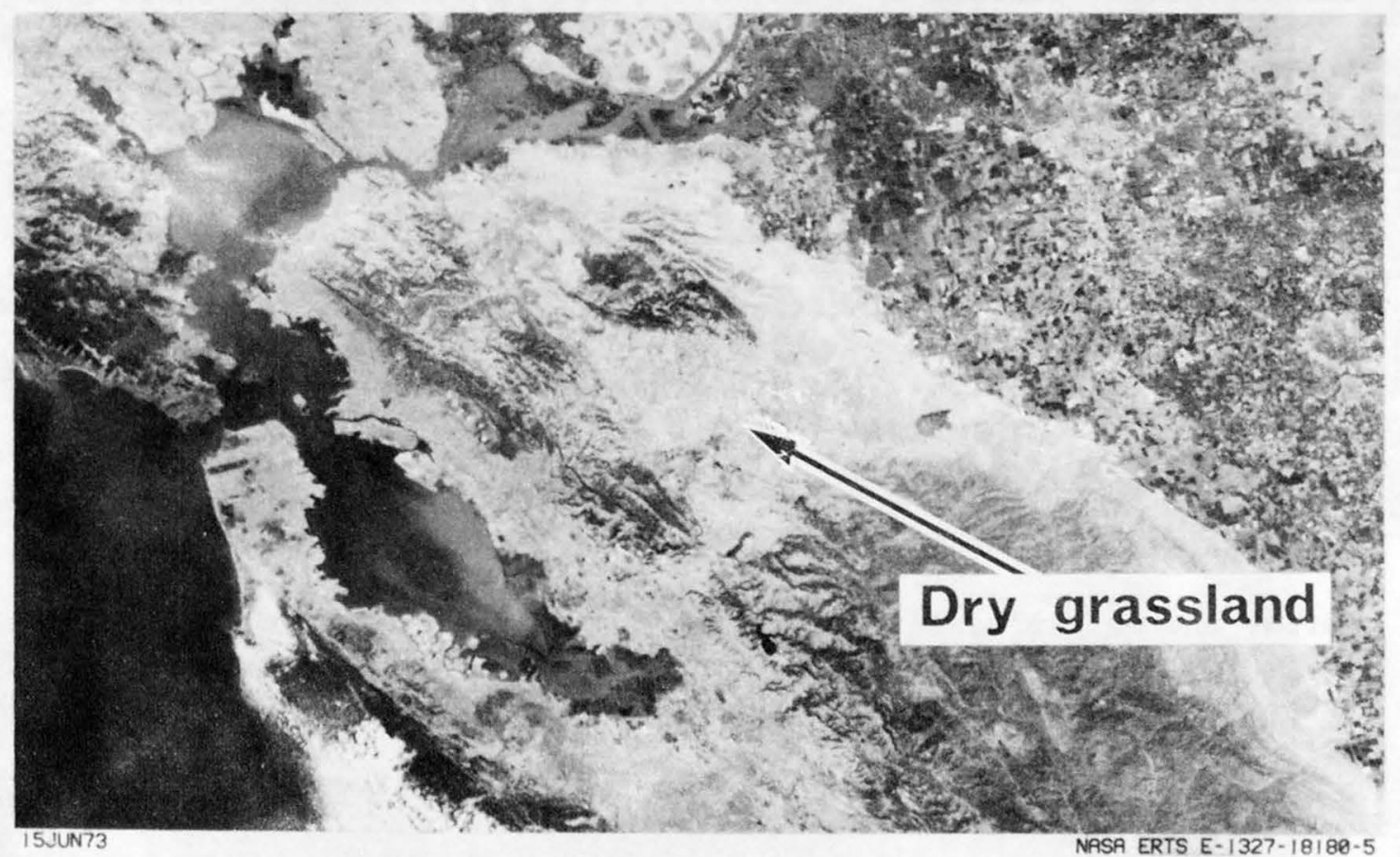

Fig. 2 - LANDSAT-1 images of the San Francisco Bay area. Comparison of sequential LANDSAT imagery permits determination of the extent and condition of annual grassland. 
monitored by use of LANDSAT data, but rapid processing and analysis of the derived information is necessary in order to make timely management decisions. At present, because of limitations in the LANDSAT processing system, data are several weeks old prior to analysis.

Center-pivot irrigation systems are readily observed on LANDSAT imagery, particularly band $5(600-700 \mathrm{~nm})$, the red band, and in false-color composite images where contrast between irrigated and nonirrigated areas is marked. In recent years deployment of center pivots has increased rapidly; Nebraska, for example, is currently adding about 2,000 per year. In some areas, the increased deployment could affect the local ground water table. Both the University of Nebraska and the EROS Program have used LANDSAT imagery to count the number of center pivots for the entire state during the irrigation seasons of 1972, 1973, and 1974. Figure 3 shows that the number of center pivots in part of Holt County, Nebraska, increased from 508 in July 1972, to 552 in July 1973, and to 740 in August 1974.

In response to the increase in coal mining activity in the Appalachians, the U. S. Geologica! Survey, in cooperation with other Federal and State agencies, is assessing the effect of coal mining on water quality, sedimentation, and streamflow of eastern Tennessee. Aerial thermal infrared imagery is used to delineate ground water water outflow, ponding on strip mining benches, storm runoff, surface 
Holt County, Nebraska...

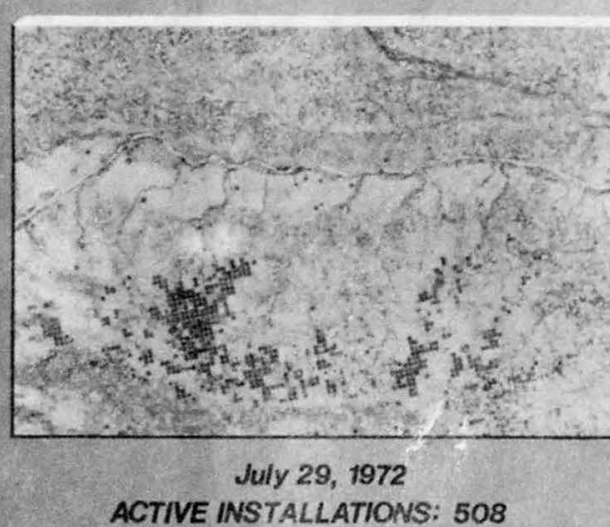

cost of statewide count

using LANDSAT: \$50-100

-98 (x)-

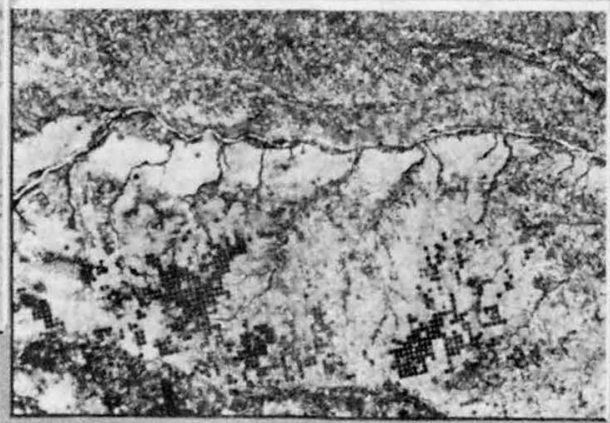

July 6, 1973

ACTIVE INSTALLATIONS:552

זंstatewide estimate: 2000 new installations per year

Fig. 3 - LANDSAT (ERTS) simplifies inventory of center-pivot irrigation systems. LANDSAT images E1006-16493-5, E1348-16500-5, E1744-16410-5 
water flow, and indications of acid mine drainage. Digitally processed LANDSAT imagery is used to delineate land cover categories including forest groups, agricultural land, and bare earth caused by strip mining. The LANDSAT analyses are useful for updating geologic maps showing strip mining activity, and for direct comparison with the status of strip mining in the late 1960 's when the field mapping was done. Figure 4 is a geologic map of the Duncan Flats Quadrangle published at a scale of $1: 24,000$ in 1970 , which shows both active and inactive strip mines at that time. Figure 5 is a map produced from LANDSAT imagery acquired April 14, 1973, and shows active and recently active strip mines in the Duncan Flats Quadrangle on that date. Bare earth areas located along the north-flowing tributaries of the Clinch River (just outside the quadrangle map to the north) include both plowed fields and detritus from the slopes, where strip mining waste is washed downward into the valleys. Both the thermal infrared and the LANDSAT data provide a base upon which to assess the dynamic environmental changes that are continuing to occur in this area.

LANDSAT imagery shows promise as a tool to monitor energyrelated development in Alaska. Examination of the vegetative cover, on a false-color composite LANDSAT image of the Umiat oilfield, revealed only one indication of scarring of the delicate tundra as a result of the intense oil exploration in this area in the late $1940^{\prime} \mathrm{s}$ and early $1950^{\prime} \mathrm{s}$. This suggested that the environmenta1 effects of oil exploration were not spreading but rather were healing. 


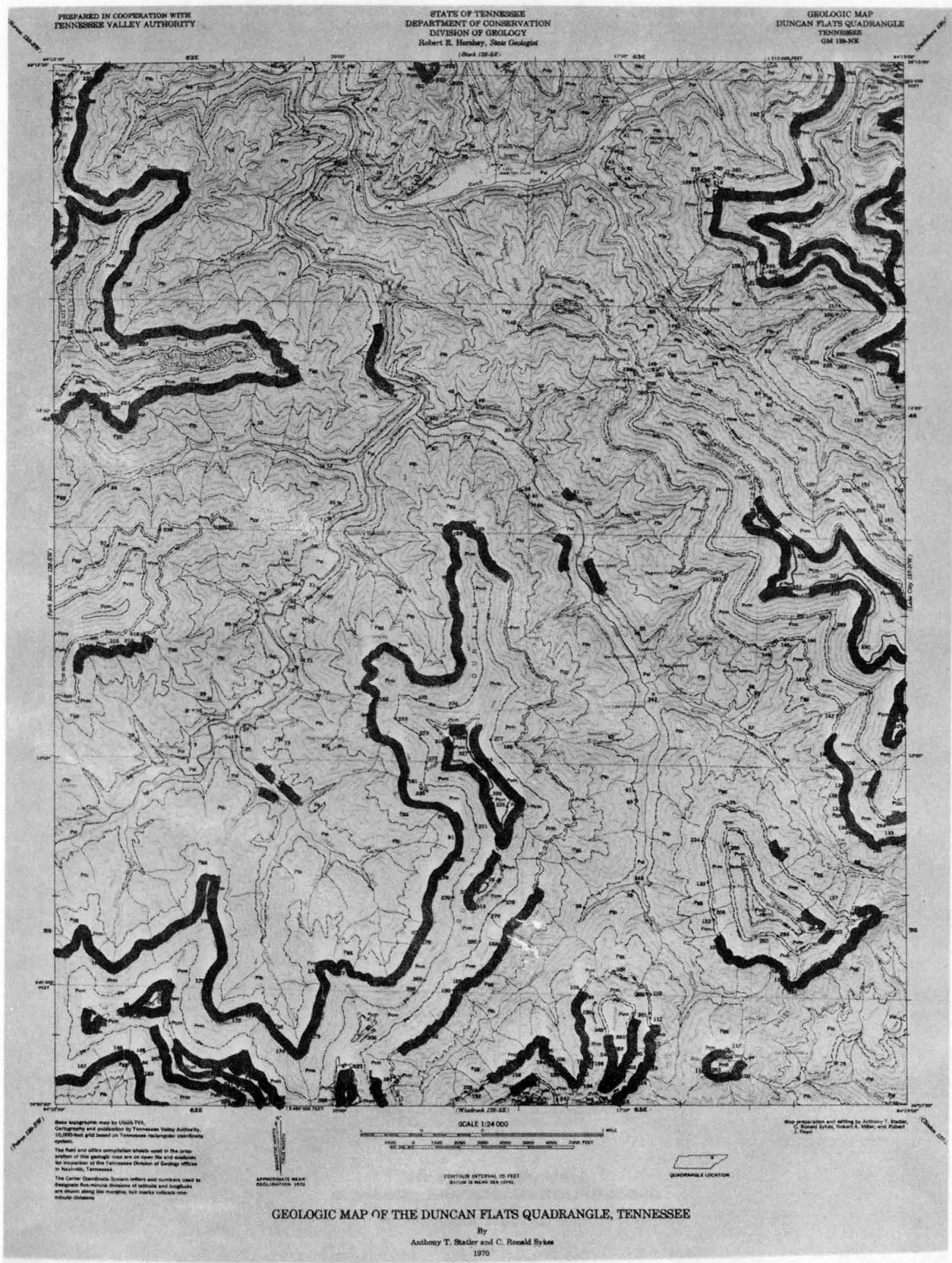

Fig. 4 - Geologic map of the Duncan Flats Quadrangle. Bold lines show extent of coal strip mines in the late $1960^{\prime} \mathrm{s}$ when field work was done. 


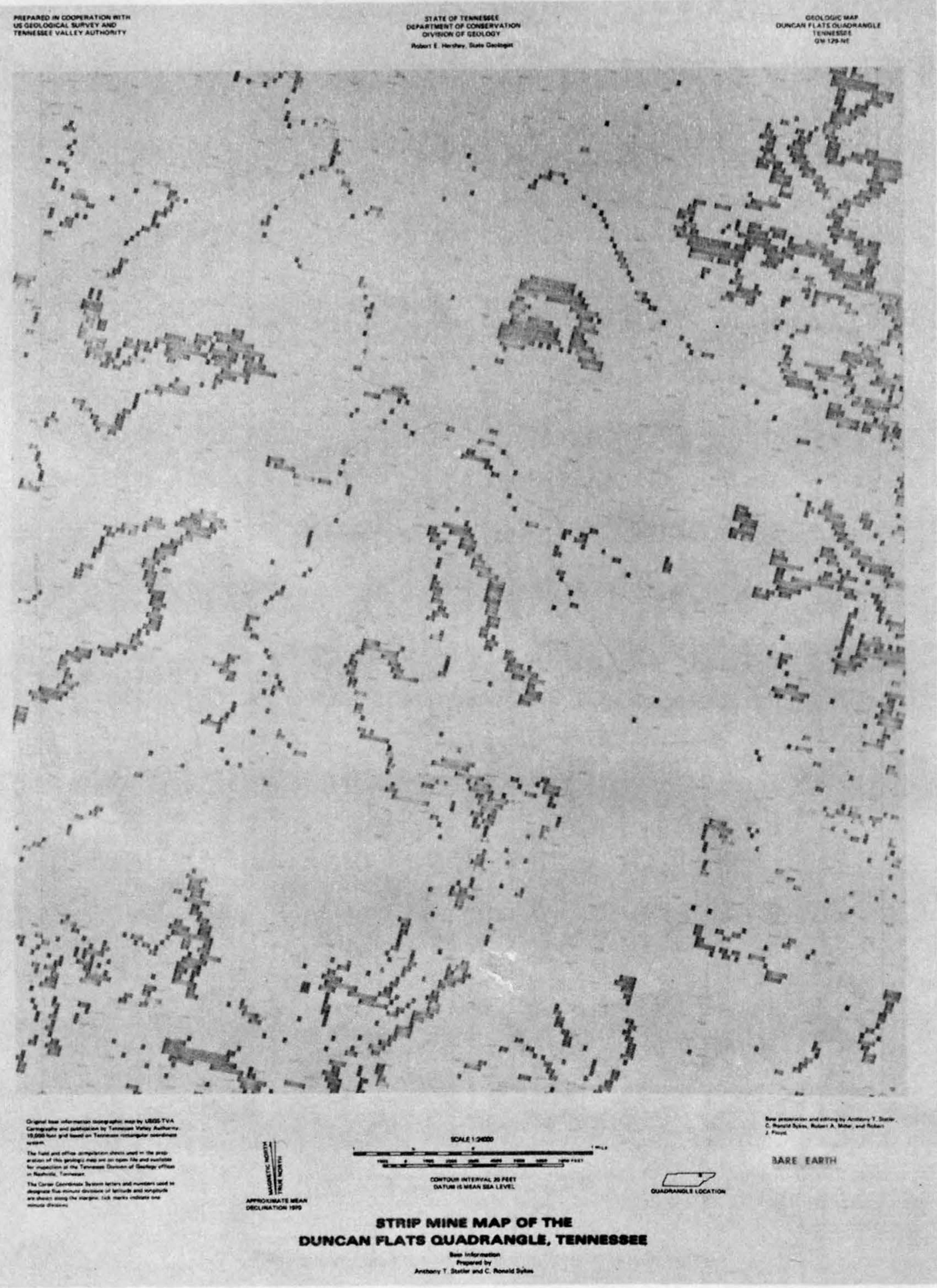

Fig. 5 - Strip mine map of the Duncan Flats Quadrangle produced from digital analysis of a LANDSAT-1 image acquired April 14, 1973. 
This conclusion was largely substantiated by low-level helicopter surveys undertaken by R. L. Detterman in the summer of 1973 and reported by Lathram (1973). One short, clear-dozed, and repeatedly used trail near Umiat still formed a marked scar.

The Canadian Centre for Remote Sensing has recently completed a study showing the importance of meteorological satellite and LANDSAT data to sea ice monitoring in the Canadian Arctic (McQuilland and Clough, 1973). The study projects large benefits for inbound and outbound shipping in this area. It also considers reduction in damage to ships by identifying navigation hazards in ice-infested waters, increased productivity for marine seismic crews, and the types of data needed for operational decisions to continue drilling or to cease drilling for petroleum in this region. The benefits for the Canadian Arctic are large. The United States may well anticipate comparable, if not larger benefits in the next few years in the Beaufort and Chukchi Seas off northern Alaska as exploration increases in the search for domestic sources of petroleum. It is imperative that timely LANDSAT data be provided to U. S. shipping in the Arctic.

A comprehensive environmental study of Iceland using LANDSAT imagery has been in progress for over 2 years. Iceland is small enough so that only 12 images cover the entire country. The topics being investigated include location of geothermal energy areas, 
tectonics of the island, planimetric revision of modern small-scale maps, monitoring of geothermal or volcanic changes within icecaps (Williams and Thorarinsson, 1973; Thorarinsson and others, 1973), identifying and mapping surging glaciers, and mapping rangeland and areas where rangeland is undergoing erosion or can be developed (Williams and others, 1974). Ecological and some geological changes occur very rapidly in Iceland (fig. 6). Results of these studies indicate that it is possible to learn much concerning similar changes in parts of the U.S. as well as other parts of the world through careful analysis of the Icelandic data. Icelandic scientists are cooperating closely with the Geological Survey in these investigation: The Icelandic Government and the Icelandic National Research Council have also been directly involved in the project.

Recent experiments have been conducted in the detection of oil floating on marine waters using LANDSAT data. This did not appear to be an area with high probability of success earlier in the program. However, reports of positive results from investigators in Israel in detecting confirmed oil spills prompted an examination by EROS scientists of the areas of possible oil spills reported by NOAA and to develop enhancement techniques that not only make the oil slicks easier to see but that permit separation of oil slicks from shallow water features and heavy silt loads in the water. Figure 7 shows an enhancement of a possible oil slick off the Virginia coast. Identification of oil floating on marine waters will have application to monitoring the nearshore marine environment; 


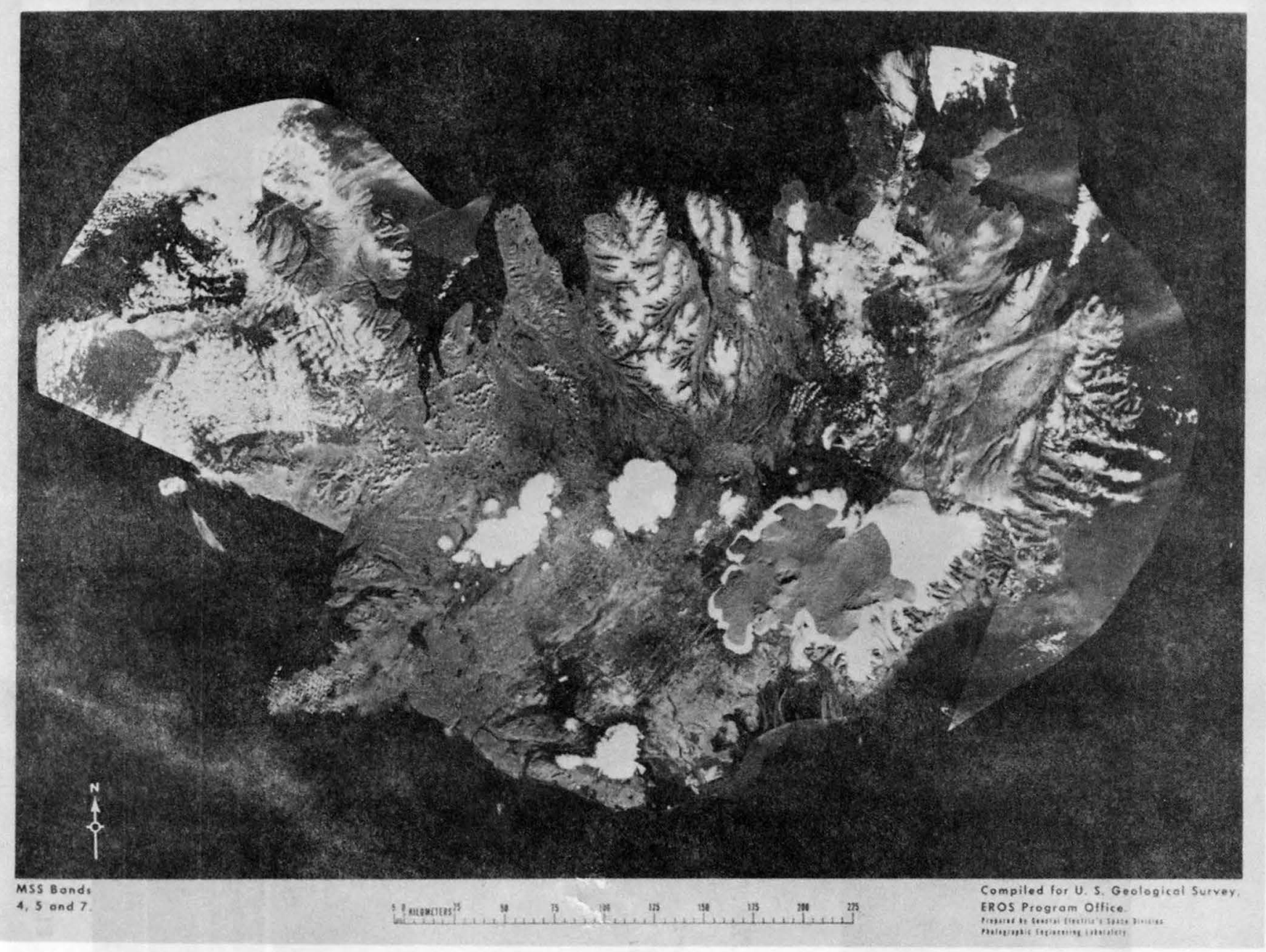

Fig. 6 - LANDSAT image mosaic of Iceland 


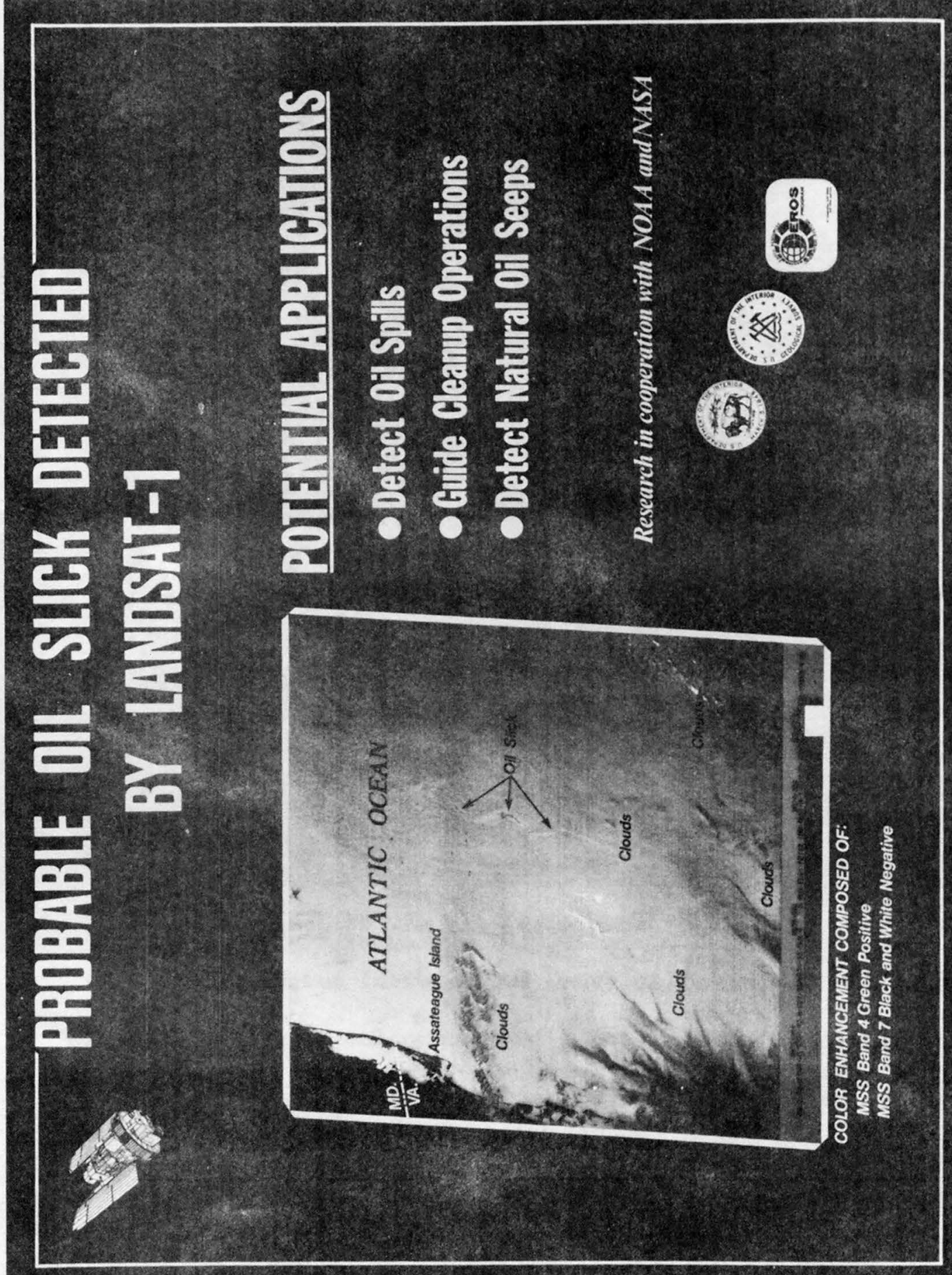


to detecting, locating, and delineating spills; to guiding cleanup operations; and possibly to aiding oil exploration along continental margins by locating natural oil seeps.

A collaborative study of 1200 river miles of the Mississippi flood that occurred during the spring of 1973 was conducted by the U. S. Geological Survey, NOAA, NASA, and the U. S. Army Corps of Engineers (fig. 8). Several investigators developed methods during this study to apply optical and digital data processing to delineation of the flooded area. This study resulted in publication of five papers in the October 1974 issue of the Water Resources Bulletin, (Deutsch and Ruggles, 1974; Weisnet and others, 1974; Williamson, 1974; Rango and Anderson, 1974; and Moore and North, 1974), which have made the results and methods available to all interested users. These results demonstrated important engineering, economic, disaster relief, and planning applications. The study has also provided the basis for a hydrologic atlas of the flood (Ruggles, written communication). LANDSAT data obtained before and during the flood were essential in conducting these studies.

As a follow on to these earlier research efforts in flood mapping, LANDSAT-2 imagery was used to map the extent of flooding of the lower Mississippi River, and the Red, Ouachita, Black, and Atchafalaya Rivers during mid and late April 1975. This work was requested by the State of Louisiana. Through special arrangement with NASA, LANDSAT imagery was received from Goddard Space Flight Center 


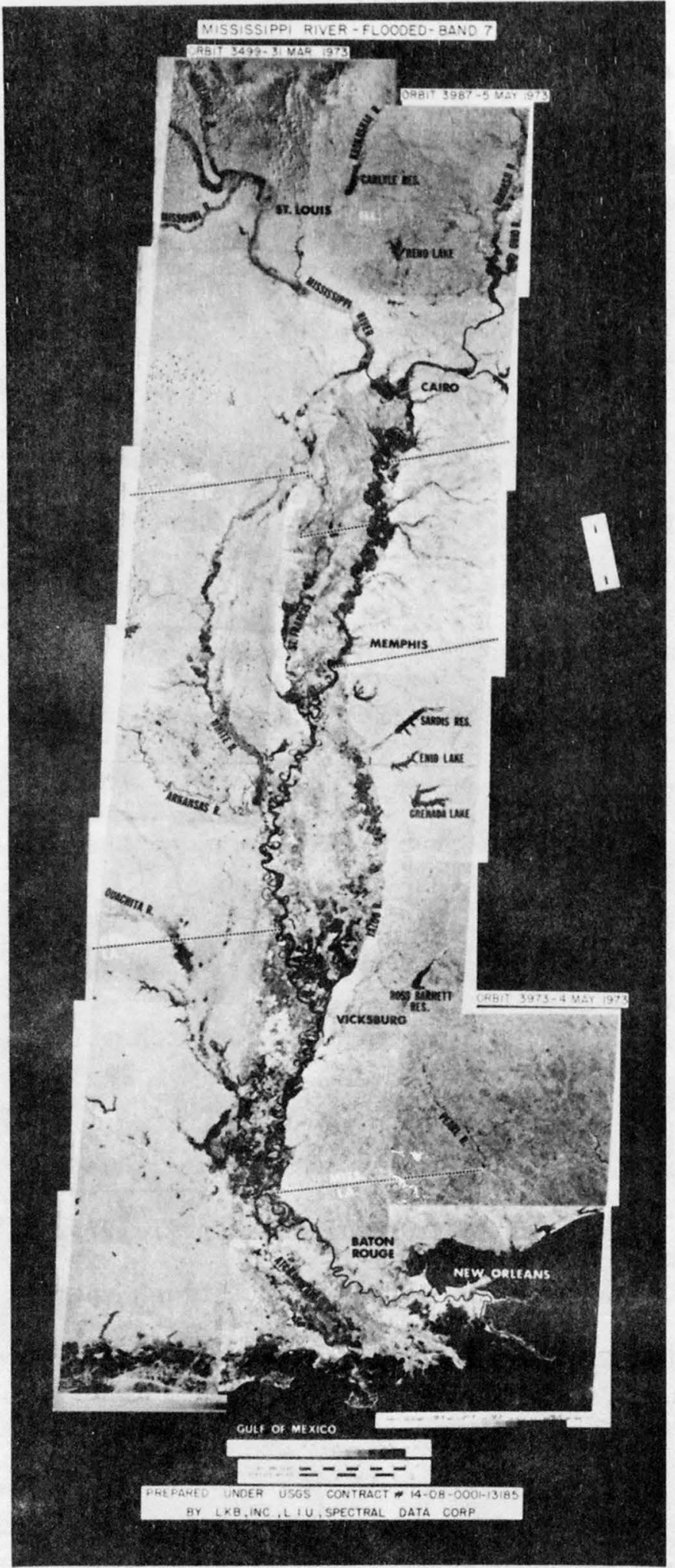

Fig. 8 - LANDSAT-1 image mosaic showing areal extent of flood of the Mississippi River (Spring, 1973) between St. Louis, Missouri, and the Gulf of Mexico. 
2 days after the satellite had made its orbital pass. Analysis of the imagery was performed jointly by personnel of the Louisiana Office of State Planning; the EROS Program Applications Assistance Facility at Bay St. Louis, Mississippi; and the Geological Survey Geography Program. By comparing unpublished Land Use Data and Analysis (LUDA) maps with flood-time LANDSAT imagery, State officials delineated flooded areas and determined that flood waters covered approximately 3,200 ha $(8,000$ a) of urban and other highly developed. regions, 120,000 ha $(300,000$ a) of farmland, 43,600 ha $(109,000$ a) of upland forest, 279,200 ha $(698,000$ a) of wetland forest, and 1,120 ha $(2,800$ a) of sand and silt areas. These totals were then broken down in accordance with areas in each parish (county) that had been flooded. Both the maps and statistics were used by the State for rapid analysis of flood damage and to document immediately the need for allocation of Federal disaster relief funds.

LANDSAT data have been used in a study of the flood on the Indus River and Chenab River in Pakistan (Deutsch and others, 1974). Figure 9 shows imagery of this area. Data used were obtained during and after the flood. Important features identified were the total extent of the flooded areas, changes in the river channel, ponded water in the flood plain as the flood water receded, leakage under a dam, location of canal breaks and leaks, and location of potential sources of ground water along mountain flanks. Excellent LANDSAT data are also available of the Cooper Creek flood in 


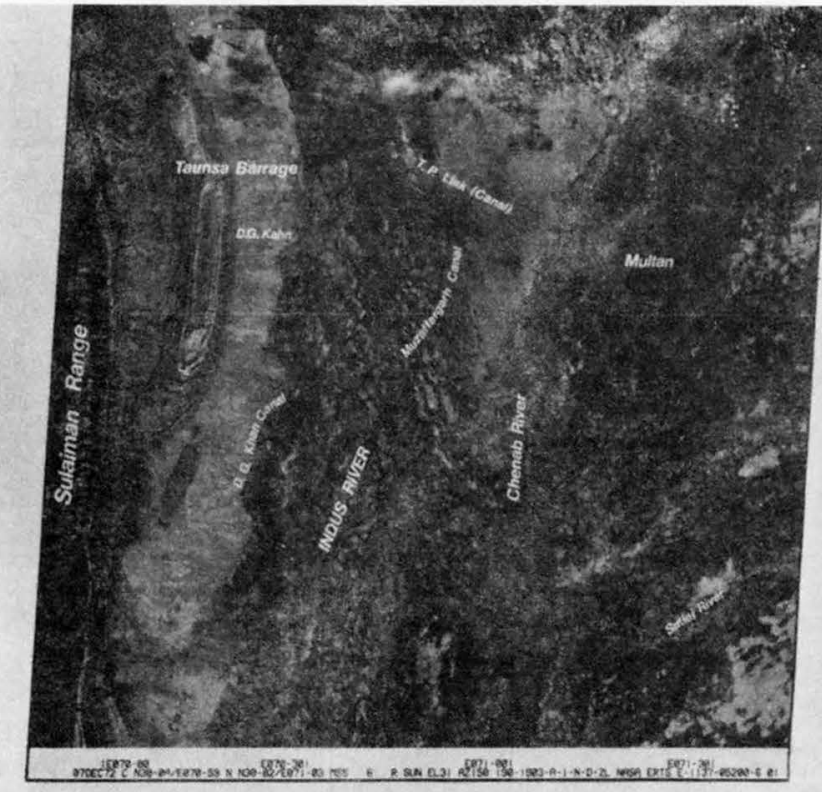

\section{ENHANCED* LANDSAT (ERTS) IMAGES}

\section{PAKISTAN FLOOD}

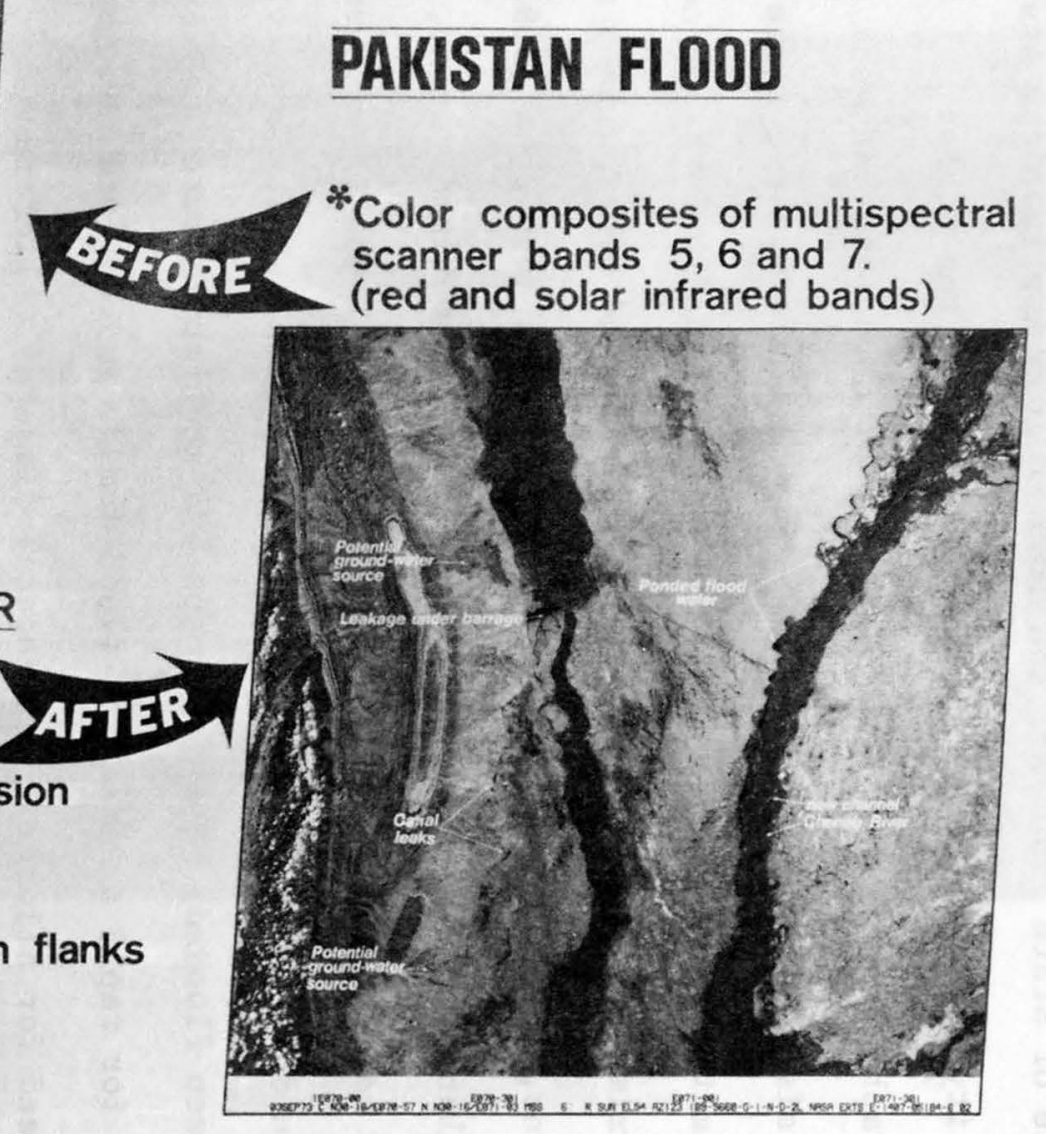

ANALYSIS OF INDUS AND CHENAB RIVER

- Flood images reveal total flooded area

- Changes in river channel

- Ponded water in flood plain after recession

- Leakage under the barrage (dam)

- Breaks and leaks from canals

- Ground-water discharge along mountain flanks

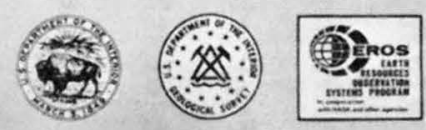


Australia. Analysis of the preflood and flood data provides similar results to those obtained from studies of the Mississippi and Indus River floods.

In addition, the LANDSAT data for the Cooper Creek flood showed a close correlation with "land systems" that have been mapped in this part of Australia. A similar correlation can be made in the flood plain using the preflood imagery. These correlations appear to be the result of vegetation expressing the differences in soil type, soil moisture, local geology, and topographic features. The relatively moist flood plain reflects these features during normal conditions. The arid higher ground does not show the features well unless there has been a recent rain. Seasonal data provide a method for rapidly mapping land systems over many arid parts of the world. The important consideration is to have a multispectral satellite capability that can obtain the data at the right time. The right time for many such localities may not occur for several years.

LANDSAT data and NASA-acquired high- and low-altitude photography are being used in the Great Dismal Swamp to map vegetation, drainage patterns, and degree of seasonal wetness (Virginia Carter, 1975).

Congressionally authorized study conducted in 1972-1973 (Public Law 92-478) concluded that the swamp should be managed as an ecological entity and that a thorough understanding of the 
hydrology was basic to formulation and implementation of a management plan. A comprehensive picture of the present day swamp-its vegetation, wildlife resources and habitat diversity--is also essential for total ecosystem management. Surface water and heavy undergrowth make the interior of this vast swamp inaccessible. Remotely-sensed data provides the only practical way of obtaining the needed information. Figure 10 is an enlargement of LANDSAT image no. 1205-15150, February 13, 1973, showing the Dismal Swamp. The entire swamp and surrounding land use can be clearly identified. LANDSAT data will be used to monitor the vegetative succession and water regime changes. If water manipulation is required to maintain the swamp, the effects of such large-scale changes in hydrology should be easily detectable. At present LANDSAT data are being analyzed and tested against high-altitude aerial photography to derive meaningful wetland categories for the future. While occasional aircraft data collections may be needed for small area studies, LANDSAT appears to provide meaningful seasonal and repetitive information for overall management.

A combination of LANDSAT, Skylab, and high-altitude NASA aircraft data have been used to identify and locate land classes in the Green Swamp area of Florida to achieve agreement in a land use plan (Coker, Higer, Rogers, and others, 1975). Figure 11 shows a LANDSAT image of this area. The classes identified included wetlands, pine flatwoods, and uplands. The wetlands are important 


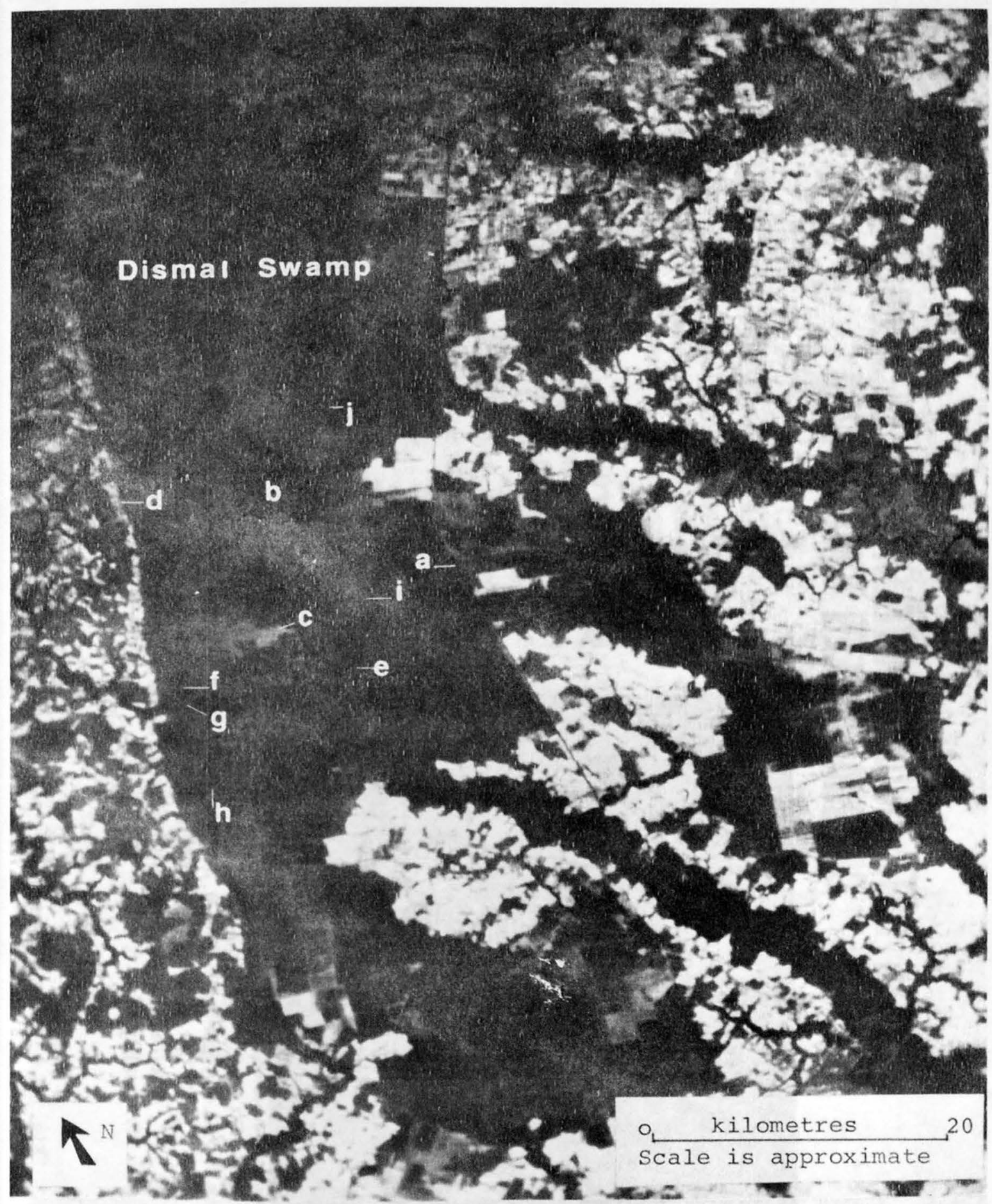

Fig. 10 - Enlarged LANDSAT-1 MSS image 1205-15150, band 7, February 13, 1973, showing Dismal Swamp. (a) Dismal Swamp Canal, (b) Lake Drummond, (c) clear-cut area, (d) western boundary of swamp, (e) Atlantic white cedar, (f) deciduous trees over standing water, (g) small marsh, (h) mesic "islands" with upland vegetation, (i) evergreen shrub bog, and (j) ditch. 


\section{ERTS DATA GUIDES DEVELOPMENT OF FLORIDA'S CRITICAL GREEN SWAMP AREA}

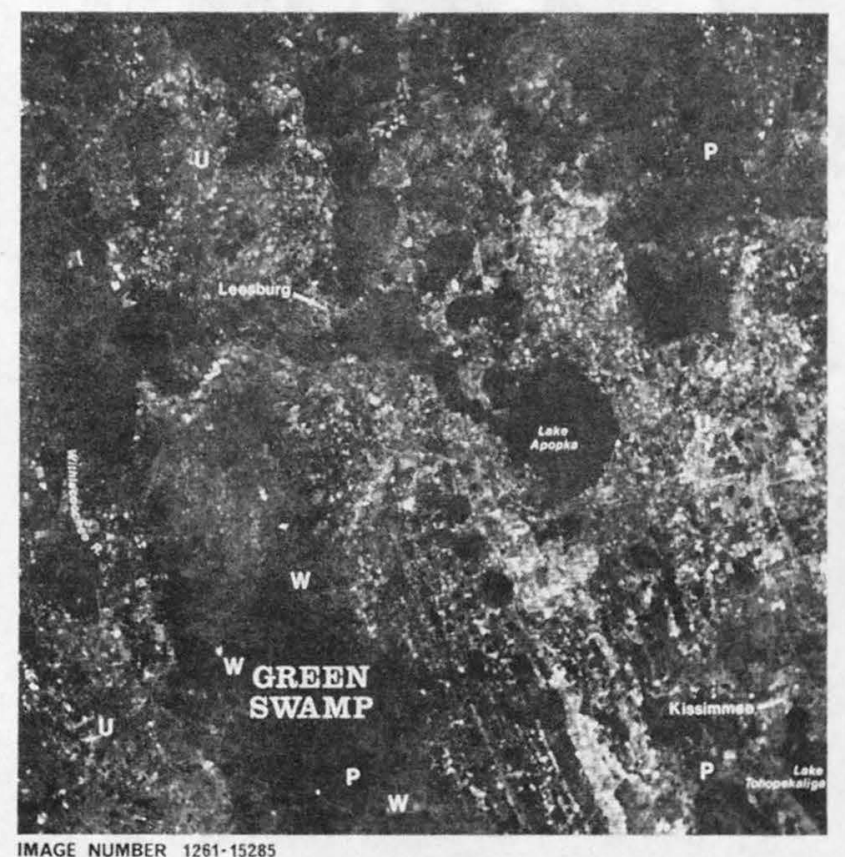

\section{LAND CLASSES DEPICTED BY ERTS}

w WETLANDS... Environmentally-sensitive areas for the preservation of wildlife and the conservation of water sources.

P PINE FLATWOODS... Seasonally inundated areas including pastures essential for preserving hydrologic balance.

(4) UPLANDS...Areas developed for agricultural, residential, and transportation uses.

$$
=0=0
$$

Analysis of space imagery provided invaluable assistance to corporations and to the State of Florida for mutual planning.... in such a way as to protect their interests in preserving natural resources, particularly water supplies and water quality". 
for conservation of wildiffe and water resources. The pine flatwoods are essential for preserving the hydrologic balance and are used as pastures. It is important that appropriate development of uplands for agricultural, residential, and transportation purposes does not seriously affect the conservation of wildlife and hydrologic balance. An agreement, based on the interpretation of remotelysensed data that considers these environmental factors, was reached between the developer of this area and the State Attorney General for a modified plan of development.

Figure 12 shows a map prepared by scientists in Bangladesh. The investigation was directed at measuring the accretion of new land to islands in the Bay of Bengal. The problem being addressed is that often, new land is used immediately for agricultural purposes before it becomes stable. When this happens, the new land is washed away during the next flood. The objective of the Government of Bangladesh is to identify the new land rapidly, plant trees on it to stabilize the land, and ultimately to open the land for agricultural use. The map required 16 manhours of interpretation and was compiled by projecting 35-mm slides of LANDSAT imagery on a piece of paper on the wall and drawing the boundaries. The map shows the stable land, new land, areas of water containing large amounts of turbidity where new land will be forming, and areas of clear water that are favorable for fishing and navigation. 


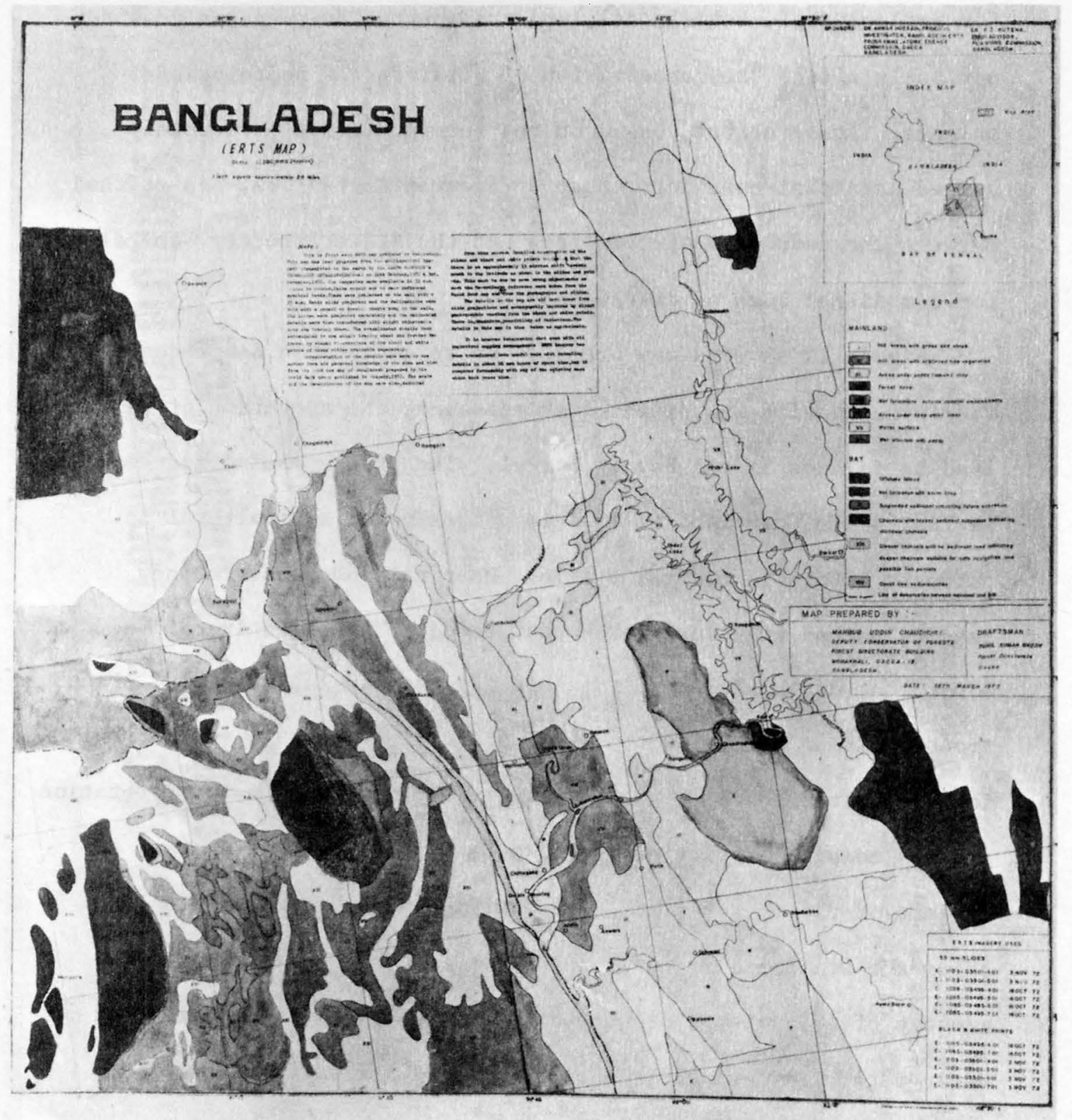

Fig. 12 - Map prepared from LANDSAT imagery by Bangladesh scientists showing accretion of new land at the mouth of the Ganges River. See following pages for text of note shown on the map. 
NOTE :

"This is first ever ERTS map produced in Bangladesh. This map has been prepared from the multispectral imagery transmitted to the Earth by the EARTH RESOURCE'S TECHNOLOGY SATELLITE (ERTS-A) on 16th October, 1972, and 3rd November, 1972. The imageries were available in $35 \mathrm{~mm}$ slides in color, false color, and in near infrared spectral bands. These were projected on the wall with a $35 \mathrm{~mm}$ Cabin slide projector and the delineations were done with a pencil on drawing sheets hung on the wall. Six slides were projected separately and the delineated details were then transferred with slight adjustments into one tracing sheet. The consolidated details thus accumulated in one single tracing sheet was further improved by visual observations of the black and white prints of these slides available separately.

Interpretation of the details were made by the author from his personal knowledge of the area and also from the land use map of Bangladesh prepared by the World Bank group published in January 1972. The scale and the co-ordinates of the map were also deducted from this source. Detailed examination of the slides and black and white prints indicated that there is an approximately 15 minutes shift towards south in the latitude as shown in the slides and prints. This must be due to some wrong adjustments as such the co-ordinate references were taken from the World Bank map and not from the photographs and slides. 
The details in the map are all hand drawn from slide projections and subsequently improved by direct photographic reading from the black and white prints. There is, therefore, possibility of variations. The details in this map is thus taken as approximate.

It is however interesting that even with all improvised mapping arrangements, ERTS imagery has been transferred into useful maps with revealing details in about 16 manhours of spare time, but it compares favorably with any of the existing maps which took years of time." 
A study was made (Robinove, 1975) at the request of USAID on the use of LANDSAT data for worldwide disaster assessment. The study concludes that floods, fire, glacier movement, and drought assessment are the disasters most amenable to satellite sensors and analysis. Table 2 summarizes the capabilities of LANDSAT data for use in monitoring disaster situations.

Table 2 - Summary of Disaster Applications of an Operational LANDSAT

\begin{tabular}{|c|c|c|c|}
\hline TYPE OF DISASTER AND & ANALYSIS & LANDSAT IMAGERY & $\begin{array}{c}\text { LANDSAT DATA } \\
\text { COLLECTION SYSTEM }\end{array}$ \\
\hline FLOODS & $\begin{array}{l}\text { Warning } \\
\text { Assessment }\end{array}$ & $\begin{array}{l}\text { Unproven } \\
\text { Excellent }\end{array}$ & $\begin{array}{l}\text { Excellent } \\
\text { Not applicable }\end{array}$ \\
\hline EARTHQUAKES & $\begin{array}{l}\text { Warning } \\
\text { Assessment }\end{array}$ & $\begin{array}{l}\text { Possible } \\
\text { Possible }\end{array}$ & $\begin{array}{l}\text { Possible } \\
\text { Not applicable }\end{array}$ \\
\hline VOLCANIC ERUPTIONS & $\begin{array}{l}\text { Warning } \\
\text { Assessment }\end{array}$ & $\begin{array}{l}\text { Possible } \\
\text { Possible }\end{array}$ & $\begin{array}{l}\text { Possible } \\
\text { Not applicable }\end{array}$ \\
\hline DROUGHT & $\begin{array}{l}\text { Warning } \\
\text { Assessment }\end{array}$ & $\begin{array}{l}\text { Possible } \\
\text { Excellent }\end{array}$ & $\begin{array}{l}\text { Not applicable } \\
\text { Not applicable }\end{array}$ \\
\hline FIRE & $\begin{array}{l}\text { Warning } \\
\text { Assessment }\end{array}$ & $\begin{array}{l}\text { Not applicable } \\
\text { Excellent }\end{array}$ & $\begin{array}{l}\text { Unproven } \\
\text { Not applicable }\end{array}$ \\
\hline CROP DISASTERS & $\begin{array}{l}\text { Warning } \\
\text { Assessment }\end{array}$ & $\begin{array}{l}\text { Unproven } \\
\text { Possible }\end{array}$ & $\begin{array}{l}\text { Not applicable } \\
\text { Not applicable }\end{array}$ \\
\hline HAILSTORMS & $\begin{array}{l}\text { Warning } \\
\text { Assessment }\end{array}$ & $\begin{array}{l}\text { Not applicable } \\
\text { Possible }\end{array}$ & $\begin{array}{l}\text { Not applicable } \\
\text { Possible }\end{array}$ \\
\hline GLACIER MOVEMENTS & $\begin{array}{l}\text { Warning } \\
\text { Assessment }\end{array}$ & $\begin{array}{l}\text { Possible } \\
\text { Excellent }\end{array}$ & $\begin{array}{l}\text { Possible } \\
\text { Not applicable }\end{array}$ \\
\hline WATER POLLUTION & $\begin{array}{l}\text { Warning } \\
\text { Assessment }\end{array}$ & $\begin{array}{l}\text { Not applicable } \\
\text { Possible }\end{array}$ & $\begin{array}{l}\text { Possible } \\
\text { Possible }\end{array}$ \\
\hline
\end{tabular}

Definitions: Excellent--Experimental results have proven the feasibility and usability.

Possible-- Experiments have not yet been completely successful but are promising.

Unproven-- Not yet tried or feasibility established, but worth experimentation.

Not applicable. 


\section{Image Maps}

LANDSAT images may be useful as a substitute for planimetric maps where such maps are out-of-date, inaccurate, or nonexistent. To be used as planimetric maps, LANDSAT images must be overprinted with a reference grid, either a latitude and longitude grid or a Universal Transverse Mercator (UTM) grid, and the horizontal accuracy of the image must be defined.

Colvocoresses (1975) gives three examples of the use of LANDSAT images to planimetrically revise out-of-date or inaccurate maps. The Geological Survey has used LANDSAT imagery to delineate new water bodies on maps such as the 1974 edition of the Virginia State base map $(1: 500,000$ scale). The 13th edition of the San Francisco sectional aeronautical chart produced by NOAA at 1:500,000 scale is noteworthy, in that, to our knowledge, it is the first time that a "theme" (open water) has been photographically extracted from a LANDSAT image and applied as a color separate to a standard cartographic product.

The Canadians have applied LANDSAT imagery to a wide range of map scales. Features on LANDSAT imagery at 1:50,000 scale cannot be portrayed at conventional map accuracy standards, but the provisional portrayal of features in their approximate location is a valid cartographic application. As of November 6, 1974, the Canadians have used LANDSAT imagery to revise four maps at 1:500,000scale; 12 maps at $1: 250,000$-scale; and 28 maps at $1: 50,000$-scale. 
New roads, new shorelines for lakes, and new power transmission lines have been plotted. IANDSAT imagery has tended to reverse the map revision cycle, in that the smaller scale maps can be corrected ahead of the larger scale maps. In fact, each scale has been revised directly from the LANDSAT image: there has been no need to derive revision information through successively smaller scales that is time consuming and of ten results in cartographic generalizations. However, LANDSAT images rarely show all of the cultural features which should be revised on a map. Use of LANDSAT at scales larger than $1: 250,000$ usually results in generalization of shapes and cultural features.

In Antarctica, the U. S. Geological Survey (MacDonald, 1975 a and b) and the British Antarctic Survey are using gridded LANDSAT images as the basis for wholly new maps and to effect planimetric revisions to previously published maps. The U. S. Geological Survey has published experimental image maps of Antarctica at $1: 1,000,000$ and 1:500,000 scales. As of September 1974, the British Antarctic Survey had published seven 1:250,000-scale image maps, each with a companion planimetric map, of Antarctica at a fraction of the cost of producing planimetric maps from conventional aerial photography.

The maplike characteristics of LANDSAT data make it possible to compile image maps of large areas. Experiments of this type have been conducted by a number of organizations. The Geological Survey has been working to find ways of preserving as much of the information as possible and still provide accurate smal1-scale image map products. 
A state-based 1:500,000-scale image map of the State of Arizona has been published. This map is receiving extensive use by the State of Arizona as a base for plotting a variety of information derived from other sources. Figure 13 shows a State Highway Map published at a scale of $1: 1,000,000$ that was prepared by the Arizona State Highway Department on this image map base. Figure 14 shows another derived map product, at a scale of $1: 1,000,000$, prepared by the Arfzona State Office of Economic Planning and Development that shows the locations of remote subdivisions throughout the State. Additional products prepared by the State of Arizona, using this mosaic as a base, include a $1: 1,000,000$-scale map showing weather station locations and 1:3,000,000-scale maps showing precipitation during the four seasons, temperature distributions during the four seasons, hours of sunshine, total solar radiation, and rates of evaportation (State of Arizona, 1975, ARIS Cooperative Publication No. 5). Use of image maps as a base for these purposes make it possible to relate many parameters directly to terrain and environmental features. Other uses that are planned for this image mosaic are a reference system for township and range locations, a base map for aeronautical charts of Arizona, an index map showing the location of orthophoto quadrangles made from NASA U-2 data, and a wall reference map to show locations of special projects such as the University of Arizona's range management delineation of range conditions. The Salt River Irrigation Project is using the Arizona State Map for aerial snow mapping in place of the standard aeronautical charts because it is easier to recognize geographic features and map the snowline on the LANDSAT map. 
ARIZOXA
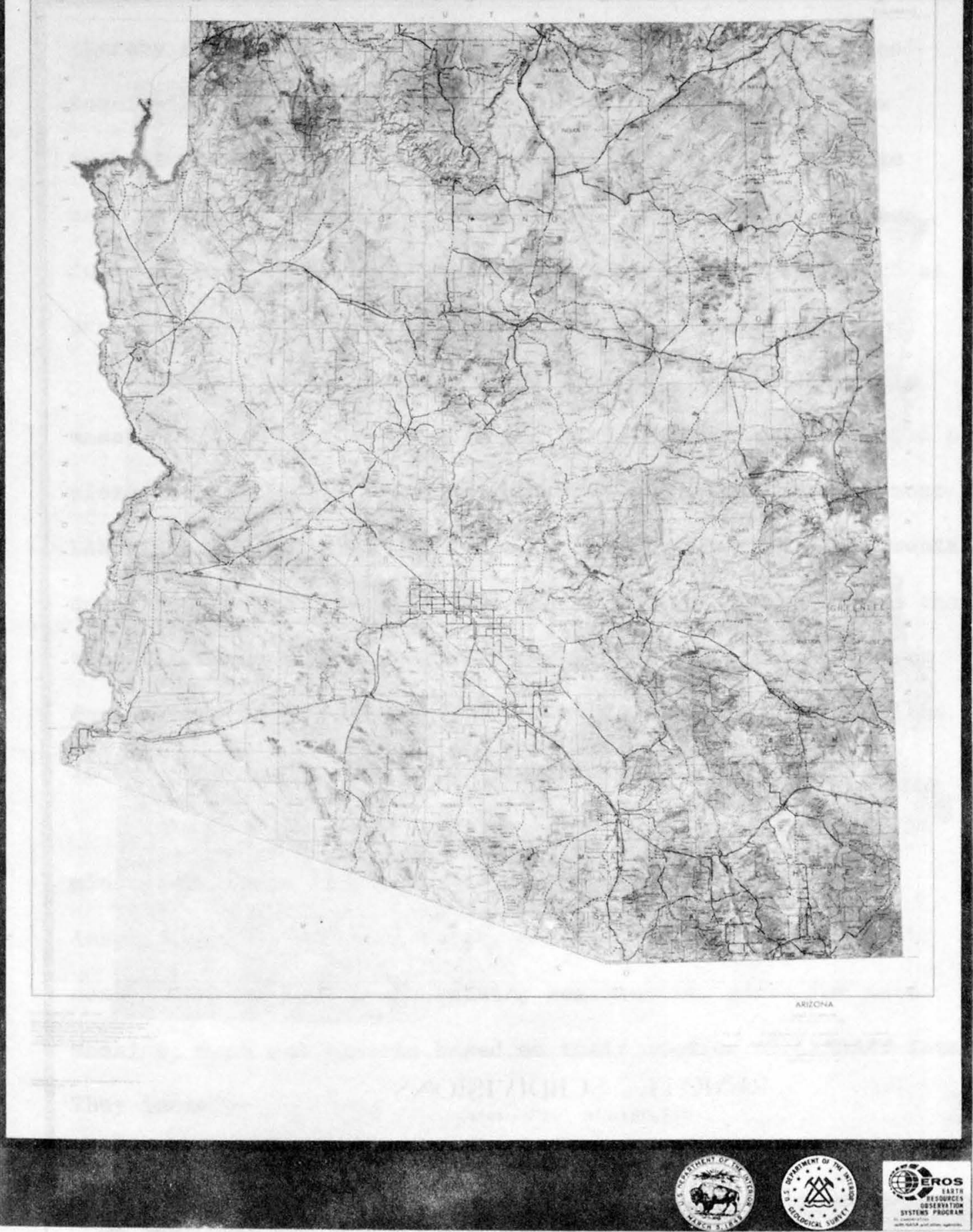

Fig. 13 - Satellite image map of Arizona. Overprint showing highways was prepared by the Arizona State Highway Department. 


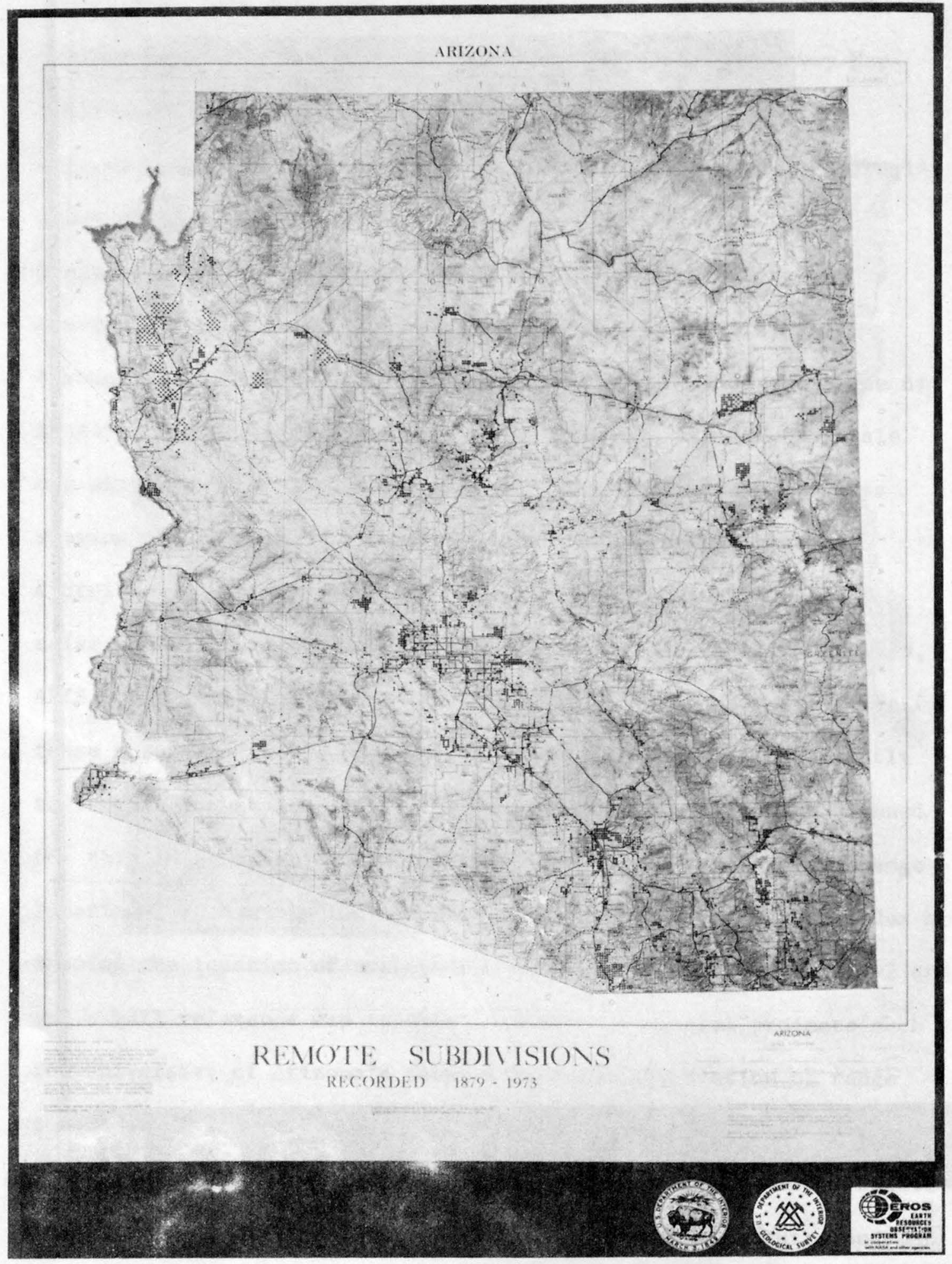

Fig. 14 - Satellite image map of Arizona. Overprint showing locations of remote subdivisions throughout the State was prepared by the Arizona State Office of Economic Planning and Development. 
A false-color image mosaic showing all of Florida at 1:500,000 scale has been published. It was made by combining photographic transparencies in different color bands to produce the image map, thereby retaining image detail not possible when conventional mosaicking methods with photographic prints are used. This technique also permitted production of black-and-white image maps at 1:250,000 scale as a byproduct. Florida was selected for this experiment because of anticipated difficulties such as ground cover, irregular shape, and number of images required.

A mosaic of the State of Nevade is in preparation. This mosaic will use digitally enhanced imagery and the colors will be closer to true color than the false-color presentations of most LANDSAT color imagery. This type of presentation is experimental and based on the expressed desires of geologists who believe that tones and colors of images should closely match those that are encountered in the field. The application to geologic problems in arid and semiarid areas is promising.

International acceptance of LANDSAT data by scientist in mineral resource industries is exemplified by Layton and Associates Pty. Ltd., of Perth, Australia, who, as commerical consultants in geology and mining engineering, offer for sale mosaics, maps and reports based on their studies of LANDSAT data. They include:

a. Photomosaic of Australia $(1: 2,500,000)$

b. Photomosaic of Borneo Island $(1: 1,000,000)$

c. Photogeological/LANDSAT Map of Collier Sheet, Western Australia 
d. Photogeological LANDSAT Map of Mt. Egerton Sheet, Western Australia

e. Tasman Geosyncline

f. Mt. Isa, Queensland

g. Ashburton-Pilbara, Western Australia

h. Yilgarn, Western Australia

i. Lineaments of the Australian Continent

j. Geologic Map of Australia with 1ineament study

k. Amadeus Basin and Environs, Central Australia

1. Arnhem Territory Study, Northern Australia

m. Circular Features of Australia $(1: 1,000,000)$

Both Bolivia and Venezuela have revised their small-scale national planimetric maps on the basis of new information provided by LANDSAT images. Argentina, Brazil, Venezuela, Bolivia, Paraguay, and Mexico are also using photographs from the Skylab missions for mapping and other applications.

\section{Products From Digital Analysis}

Since July 1972, LANDSAT-1 and -2 have collected well over 500,000 images of the land areas of the Earth. A few areas remain to be imaged for the first time, but there are many areas for which 20 images or more have been acquired over the 3-year period. While many images have been studied by standard photointerpretation techniques, new data and consequently, new information is accumulating in the EROS Data Center faster than these conventional interpretation 
methods can provide analyses. Although this stored data will always have a high intrinsic value for its historical information content, greater benefits can be derived if the data are analyzed rapidly for specific purposes so that changing phenomena can be field checked and management decisions made during the period of change. In order to accomplish this efficient analysis, systems must be employed to reduce the analytical period.

In the past 3 years, several generations of color additive viewers, density analyzers and digitizers have been developed by commercial enterprises. The same is true in the field of analytical computer systems. New models under design and in development offer promise of even better, smaller, and cheaper devices that can be easily incorporated into operational programs. Software programs to accompany these systems are developing at an equally rapid rate as knowledge of the LANDSAT system grows. The demand for computer compatible tapes of LANDSAT images has far exceeded NASA's and the EROS Program's original estimate. For example, the demand for LANDSAT computer compatible tapes has grown from $\$ 1,600$ in FY 73 , to $\$ 36,480$ in FY 74 , to $\$ 164,000$ in FY 75 (Watkins, 1975). Capabilities to produce and copy magnetic tapes have required augmentation of NASA and EROS facilities.

Much of the research and development of new software programs have been conducted in more than a dozen universities with support from NASA, USDA, USDI, and other Federal agencies. Research by these contract groups should continue to be supported so that future developments can continue at a steady rate. In addition, 
in-house research, using rapidly developing computer analysis technology, must be conducted to insure technology transfer to operational programs and projects in a timely manner as newer techniques and systems are proven.

There is a need for rapid extraction of themes such as:

a. Sea ice vs. open water distribution in the Arctic for navigation,

b. Snow-1ine delineation in mountainous regions for better water runoff estimates involving hydroelectric power and irrigation uses, and

c. Grassland distribution and vigor in western grazing lands to improve cattle production.

Facilities for standard production of themes should be developed, tested, and implemented.

Automatic determination of land-cover classes is undergoing rapid development. Figure 15 shows a land-use map prepared by the Geological Survey from NASA aircraft data acquired at the time of the 1970 Census. Figure 16 shows a more recent analysis of the same area using LANDSAT data from two times of the year, April 1973 and October 1973 (Wray, 1975). This new product required computer analysis of 2 million picture elements from each of the eight data channels obtained from the two LANDSAT passes, a total of 16 million measurements. In the final map, 12 land-cover classes have been delineated. It took approximately 20 man-weeks to compile and 2 years 


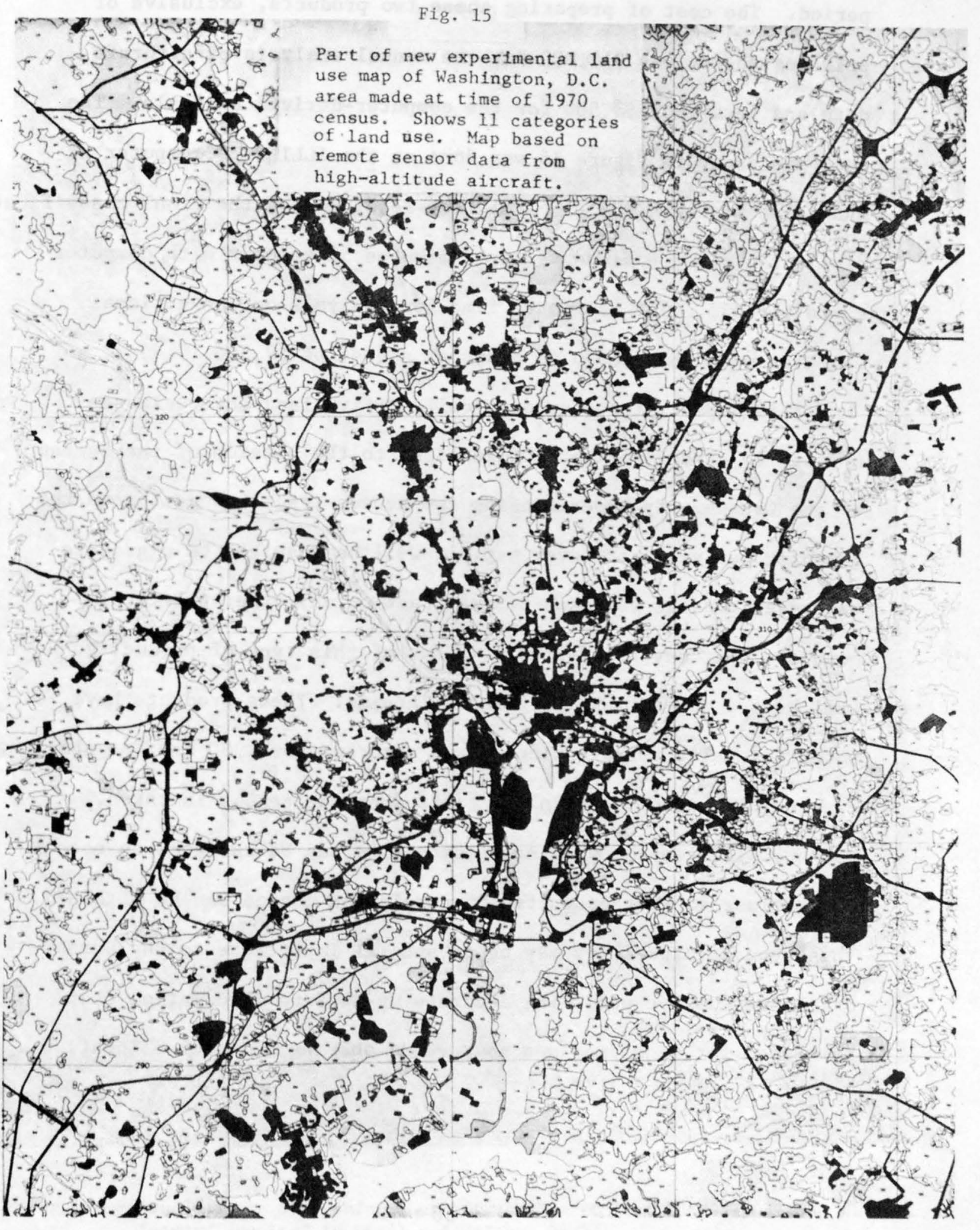


to publish the 1970 land-use map. The new experimental product was available in photographic form after 3 weeks of effort over a 2-month period. The cost of preparing these two products, exclusive of printing costs, was $\$ 12,000$ for the manual analysis of aircraft data and less than $\$ 3,500$ for the computer-derived analysis. The analysis shown in Figure 16 was done on the ILLIAC IV computer at NASA Ames Research Center. The time required for the final classification of all the picture elements was 7 minutes 58 seconds with computer costs of $\$ 333$. The estimated time for analysis on conventional. computer would have been 25 hours at a cost of $\$ 7,500$.

This capability to automatically derive land-cover classes appears to have important applications to the mission of the Bureau of the Census. By superimposing the census tract boundaries on the computer derived land-cover map, it will be possible to aggregate the cover classes for each census tract or any other political boundary that may be desirable. Uses of this type of product go well beyond conventional land-use planning. These products have potential value for planning census programs for 1980 and for updating census information between the times when the census is taken. For example, average population densities can be assigned to each cover class so that estimates of population change can be obtained. This type of capability may be of special importance to the Bureau of the Census for providing accurate up-to-date information that is needed for such programs as revenue sharing and fuel allocation. 


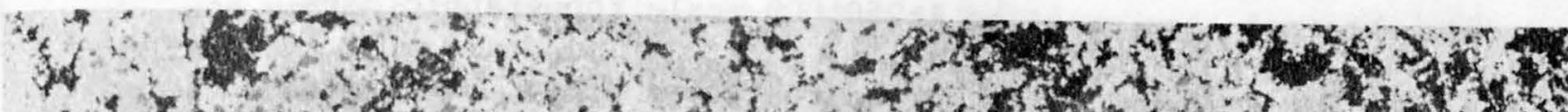

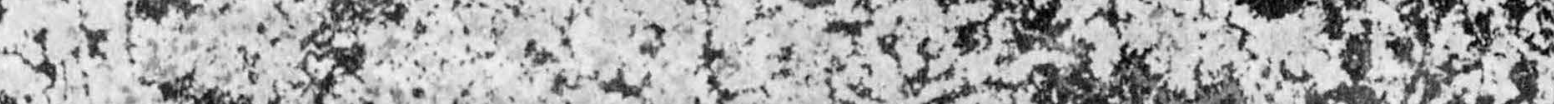

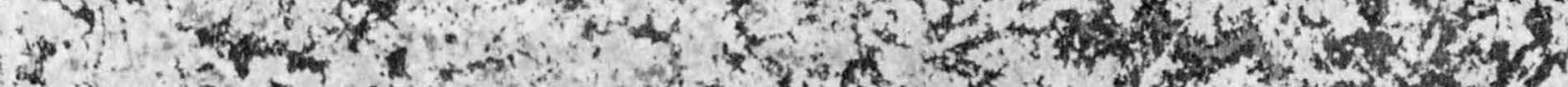

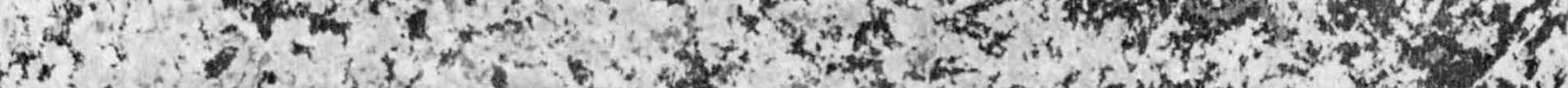

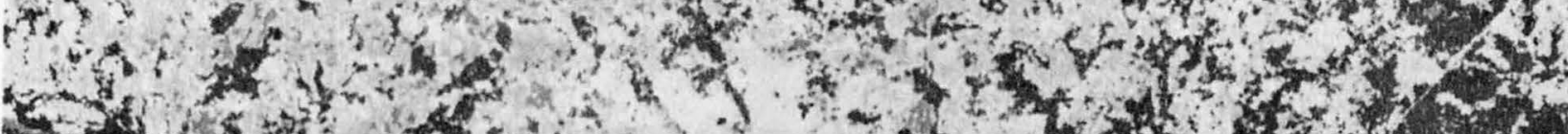

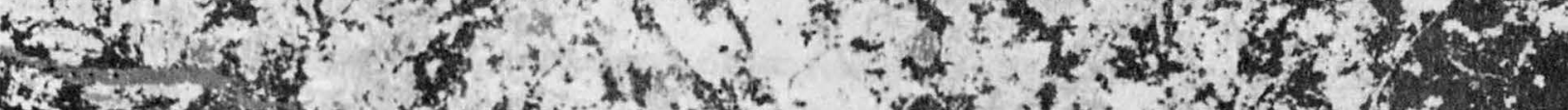

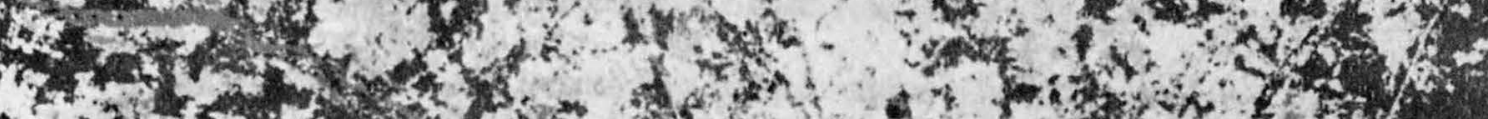

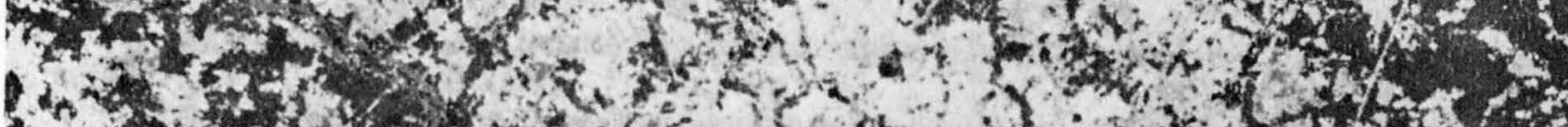

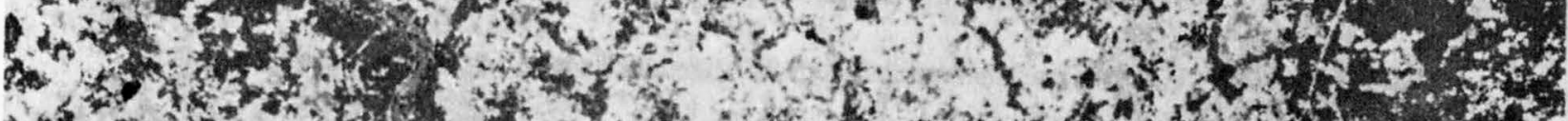

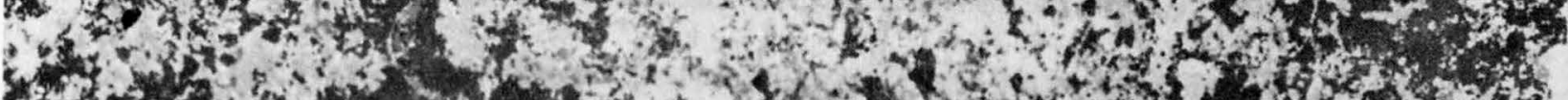

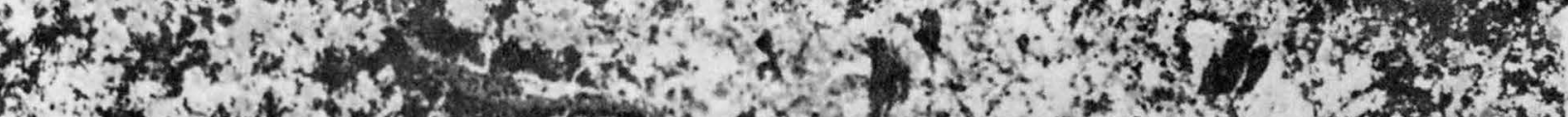

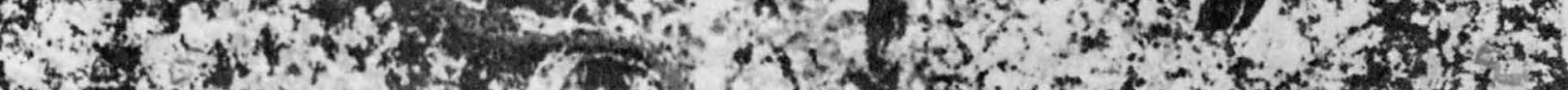

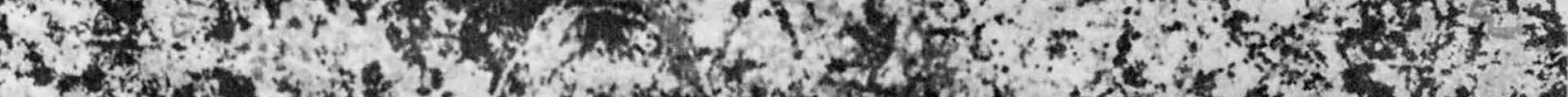

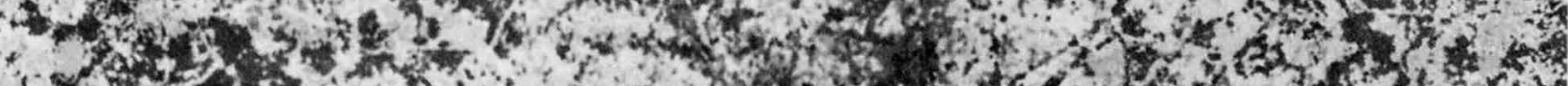

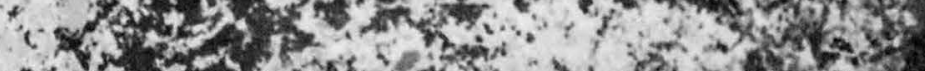

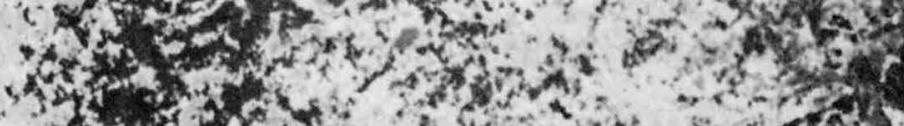

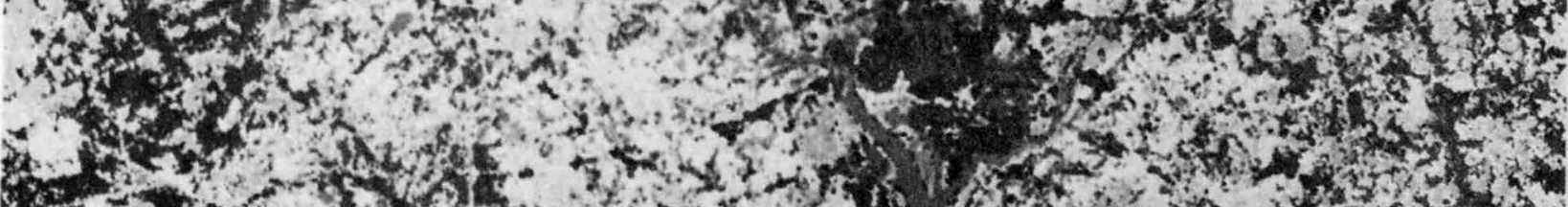

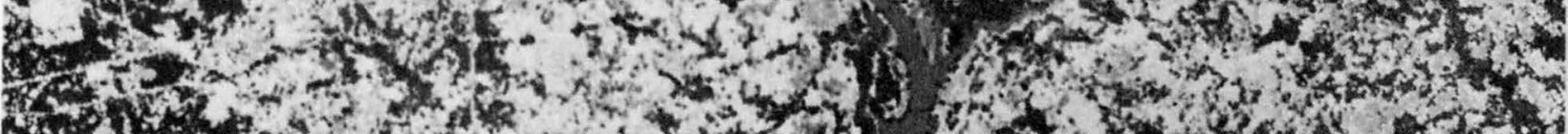

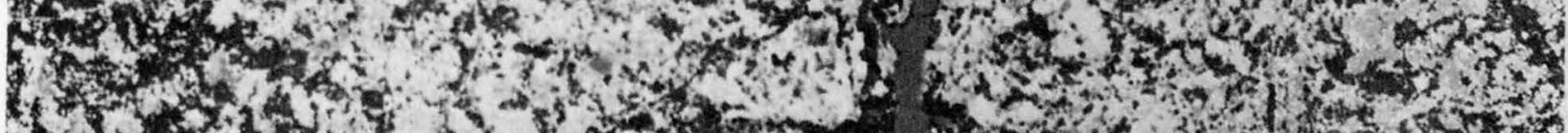

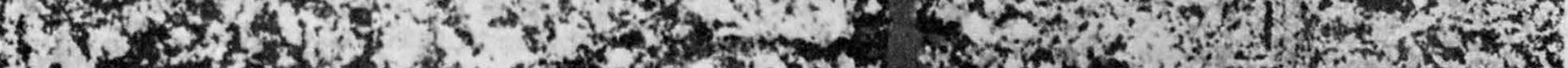

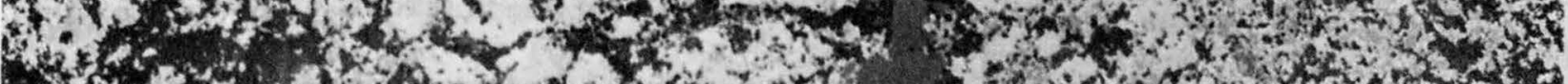

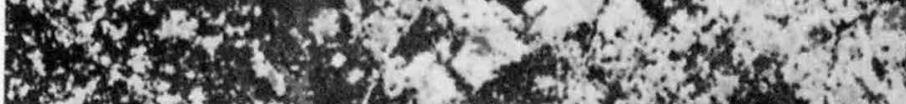
H.

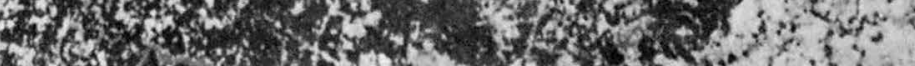

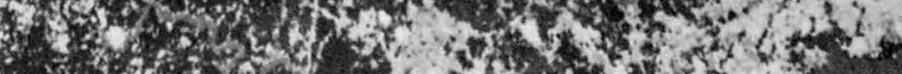

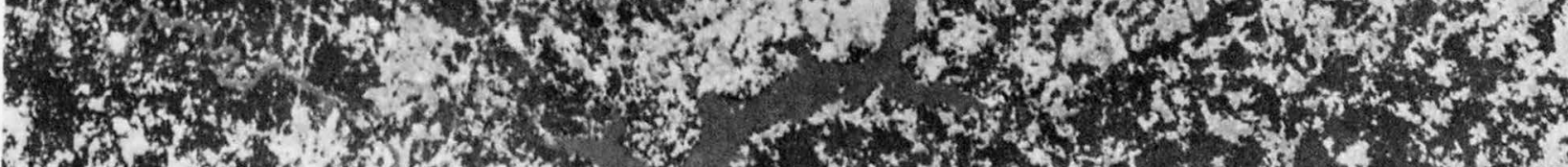

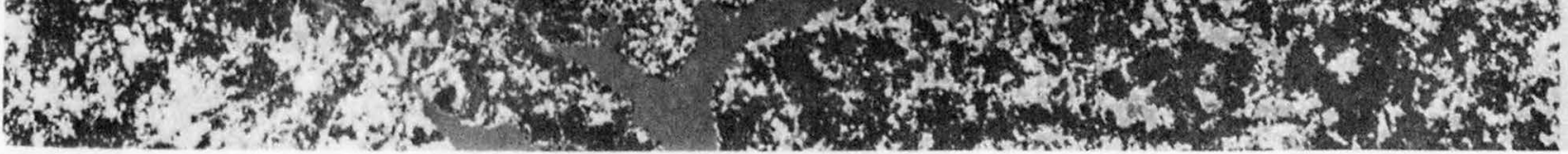

Fig. 16 - Land use map of Washington, D. C., prepared from LANDSAT imagery acquired in April and October 1973. 
Geological Survey personnel at Flagstaff, Arizona, have produced a computer-generated stereo pair from a single LANDSAT-1 image of the Gunnison River area, Colorado. Parallactic displacement commensurate with terrain relief was introduced by manipulating each picture element in accordance with digital terrain elevation data obtained from existing 1:250,000-scale topographic maps (Batson and Eliason, 1975). This recreated scene, containing parallax, is used as a stereo mate to the standard LANDSAT image. The Gunnison River stereo pair has been reproduced in black-and-white, color, and color infrared. Stereoscopic rendition of topographic detail is probably the single most important attribute in geologic and geomorphic interpretation of both aerial photography and space imagery. The addition of stereoscopic viewing capability to LANDSAT imagery is considered to be a significant research development because it combines the stereo view with another important attribute in regional analysis, the synoptic view of a large area under lighting conditions which are consistent for the entire scene. At the request of resource agency personnel of the Pacific Northwest States and the Land Resource Inventory Task Force of the Pacific Northwest Regional Commission for recommendations on the use of remote sensing in State resource inventory and management problems, the EROS Program and NASA Ames Research Center suggested the establishment of a Pacific Northwest Demonstration Project which was subsequently approved by the Governors of Idaho, Oregon, and 
Washington in October 1974, and is now being implemented. This project envisions the conduct of land resource analyses and inventories of selected areas by employees of the Pacific Northwest States, at Ames Research Center, receiving support, assistance and guidance from USGS and NASA resource and technology specialists, and using both satellite and high-altitude aircraft data provided by EROS and NASA. The goal of the project is to equip personnel of the State resource agencies with the knowledge and skills necessary to utilize the synoptic, multispectral, multitemporal and digital characteristics of LANDSAT data in providing part of the information required to formulate appropriate and effective management decisions by the State agencies. Problem areas for initial studies have been identified by 28 participating State agencies, a number of workshops have been held, and specialists from the EROS Data Center, USGS Geography Program, and NASA Ames Research Center are working with State personnel.

\section{Data Collection Platforms}

Tests of the Data Collection System flown on LANDSAT have indicated that satellite technology can be used as a cost-effective method for collecting environmental data on a truly national scale. The U. S. Geological Survey, and the U. S. Army Corps of Engineers are large potential users of this technology for hydrologic data collection and have taken leading roles in demonstrating the operational use of this technology. 
A significant demonstration is the use of the LANDSAT Data Collection System with the Survey's national computer system. NASA is providing real-time Data Collection Platform data via a dedicated land line from the Goddard Space Flight Center to the USGS National Center in Reston, Virginia. Data from the platforms, which are distributed across the United States, are entered Into the Survey's computer data base, from which they can be retrieved by over 150 computer terminals located in project, district, and regional offices. The LANDSAT system can collect remote site data from most of the United States and makes it possible to use the USGS computer system to quickly process and disseminate data to users across the country.

There are two benefits resulting from integration of a satellite data collection system with the Survey's computer network. It will be possible to automatically collect and process data, eliminating the labor-intensive task of manually retrieving and preprocessing the data, as is done now. Secondly, the data will be avallable in real-time for use by resources management agencies, significantly enhancing their ability to monitor and safeguard the environment. Other specific uses of Data Collection Platforms include the attempt to monitor the effectiveness of cloud-seeding research for Project Skywater in Custer County, Montana. Figure 17 illustrates the field layout and communications links that are being used for this investigation. Data from 64 rain gauges are relayed by 


\section{SATELLITE RELAY USED TO ASSESS GLOUD SEEDING}

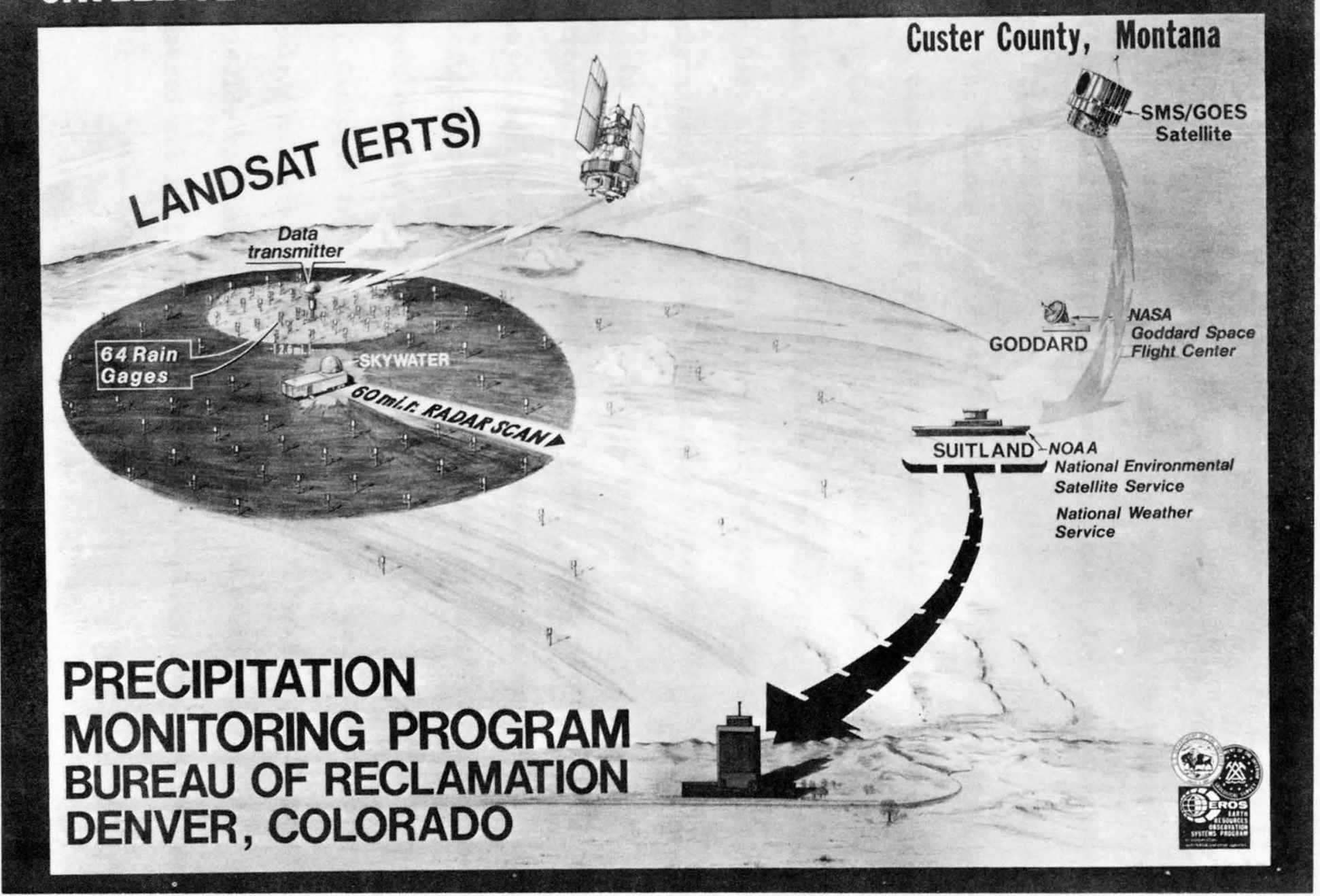

Fig. 17 - Data collection platform field layout and communication links being used to assess the effectiveness of cloud seeding for Project Skywater, Custer County, Montana. 
Data Collection Platforms through LANDSAT and then to Goddard Space Flight Center. The data are then transmitted by land lines to the Bureau of Reclamation offices in Denver, Colorado. It is essential to have rapid and reliable transmission of these data to evaluate the effectiveness of these dynamic experiments. As Figure 17 indicates, plans call for conducting part of this and later experiments using the Data Collection System on the NOAA Synchronous Meteorological Satellite/Geostationary Operational Environmental Satellite (SMS/GOES).

The Arizona Salt River Irrigation project is conducting a joint cost-sharing project using data collection platforms with the USGS in Arizona. A helicopter will be used to check the station records periodically after rainfall/runoff events occur. The Data Collection Platforms will be used to notify the project headquarters office when events are occurring.

In addition, the USGS has installed a remote environmental monitoring system on Black Mesa, a coal-strip mining area on the Navajo Indian Reservation. The monitor records and relays precipitation, stream flow, water salinity, acidity, and dissolved oxygen content.

Geologic experiments with Data Collection Platforms have been highly successful and demonstrate that it is feasible to create a worldwide volcano monitoring system. The primary parameters measured are tilt of the slopes of the volcano, and the number of 
earthquakes of various sizes within the area of the volcano. Both of these quanitites are indicators of potential eruptive activity by the volcano, and can be used as precursor events to predict eruptions when the characteristics of individual volcanos are known. Data from LANDSAT Data Collection Platforms of the February 1973 eruption on Fuego Volcano in Central America showed precursor events prior to the February 1973 eruption (Eaton and others, 1974). Other parameters that can be measured are temperature and composition of gases excaping from fumaroles. These also may be of value for future prediction purposes when more is learned of their relation to activity of individual volcanos.

Work is proceeding closely with NOAA to develop the use of the Data Collection System on SMS/GOES. A Data Collection Platform has been developed that is compatible with either LANDSAT or the operational SMS/GOES. These instruments are being manufactured at the present time. Deployment to field sites will start in the late summer of 1975. Many of these instruments will be used in a truly operational mode. This is a particularly attractive approach because SMS/GOES has a reasonable assurance of continuity. The number of platforms that can be serviced is large and the times of data acquisition are not limited to orbital passes of the satellite. Use of the Data Collection Platform that is compatible with both LANDSAT and SMS/GOES will provide the opportunity to evaluate both systems under operational conditions. As a result of operational tests, it will soon be possible to specify the costs and benefits of adopting this technology as an operational tool. 
The objective of future capabilities discussed in this section is to add to our basic knowledge of the Earth. In some cases, the need for this knowledge has direct and immediate areas of application related to energy, minerals, food, fiber, and protection of the environment. In other cases, the need for knowledge is for scientific purposes, such as measurement of movements in the crust of the Earth or global measurements of the magnetic field and its change with time.

The capability to use space for acquiring data has opened many new possibilities that would be impractical by any other approach. Both the meteorological satellites and the Earth resources satellites have demonstrated capabilities for worldwide monitoring. There is much more to learn in both of these areas to obtain the maximum benefit from our ability to use space. There are also new areas where experiments and ideas are in their early stages of development. Complementary uses of space, aircraft and ground investigations are beginning to be developed. Each of these vantage points has both advantages and disadvantages. The design of the most efficient approaches to obtaining solutions to problems related to the Earth, by using each of these vantage points, will be an area for much future research.

At the present time, our ability to provide data and certain types of information products in a timely and meaningful way and to integrate these data into the information systems where they are 
needed is severely limited. Adequate data processing and data management systems are often neglected in the development of new technology. Responsibilities for implementing such systems are often divided between governmental agencies and are difficult to coordinate and implement. They are, however, the vital link between measurement technology and use of the data.

A number of additional measurement capabilities can be developed during the next few years that will greatly add to our ability to understand the Earth. The topics discussed in the remainder of this section are not exhaustive. They are examples of research that has been done, and where the technology and ability to use the data can be easily implemented. More areas of value will become practical as research continues.

\section{Precision Measurements of Intercontinental Distances}

Geological and geophysical studies have shown that large movements of portions of the Earth's crust have taken place during geologic time. Some areas are subject to geologic hazards as a result of movements taking place at the present time. The occurrence of mineral and energy resources is closely linked to geologic structures that have resulted from these movements.

The rates, direction, location, and causes of crustal movement have been a puzzle in geology. A major difficulty in understanding crustal movements has been in our inability to make precise measurements over large distances and to be able to repeat these measurements at intervals of every few years. Hypotheses concerning plate tectonics and sea floor spreading have been a major step forward in providing the capability to design meaningful experiments. New capabilities 
for precise measurements, such as very long base line interferometry and laser ranging to satellites, offer the first real hope of conducting experiments to test these hypotheses. The U. S. Geological Survey (1965, p. 27) states that horizontal and vertical displacements "would have to be determined within less than one decimeter; if coordinates could be determined more precisely, movements could be detected over shorter intervals." In many cases it will require a decade or more of data acquisition using these measurement techniques to establish the precise rates of crustal motions. These measurements will be essential to understanding global tectonics. They will also form a basis for determining the effects of sea floor spreading and plate tectonics on continental masses. This information will be essential for prediction and possible control of some geologic hazards.

An improvement in our understanding of the dynamic mechanisms that are taking place in the crust at the present time is needed to adequately describe the processes that have taken place throughout geologic time. The difficult task of reconstructing the tectonic history of the Earth will be a major step forward in explaining the occurrence of mineral resources and in aiding us in our search for new resources.

\section{Global Measurements of the Earth's Magnetic Field}

During the past 5 years the U. S. Geological Survey and Goddard Space Flight Center have cooperated in the analysis of presently available satellite magnetometer data. The principal objective of 
this project has been the identification of anomalies having geological significance. Additionally, these data are used in fulfilling our Federal responsibility for supplying geomagnetic information for use in navigation, charting, and as a reference in geophysica1 prospecting.

Even though the presently available satellite magnetometer data are not particularly suited for analysis of geological anomalies, the work done in this project indicates the potential for a satellite magnetometer as a geological/geophysical tool. Recently, a preliminary global magnetic anomaly map has been produced by analysis of this satellite data (Regan and others, 1975). Verification of several distinct anomalies was obtained by examining detailed satellite data and by comparison with available aeromagnetic and geologic data. One of the most striking anomalies occurs in central Africa (fig. 18). This anomaly, termed the Bangui anomaly, was discovered by satellite and confirmed by aircraft measurements. A detailed interpretation of this anomaly indicates that it is caused by a massive, complex regional geological body that has several associated major mineral deposits.

The global map reveals that the Bangui anomaly is not unique and indicates that such studies using satellite data could have a significant application to energy and mineral studies on continental or global scales. However, to have practical application it is necessary to obtain measurements from satellites that are designed for such studies. A global survey, proposed by the USGS, using a vector magnetometer in a low-altitude satellite would provide the necessary data for such applications and also establish dense global 


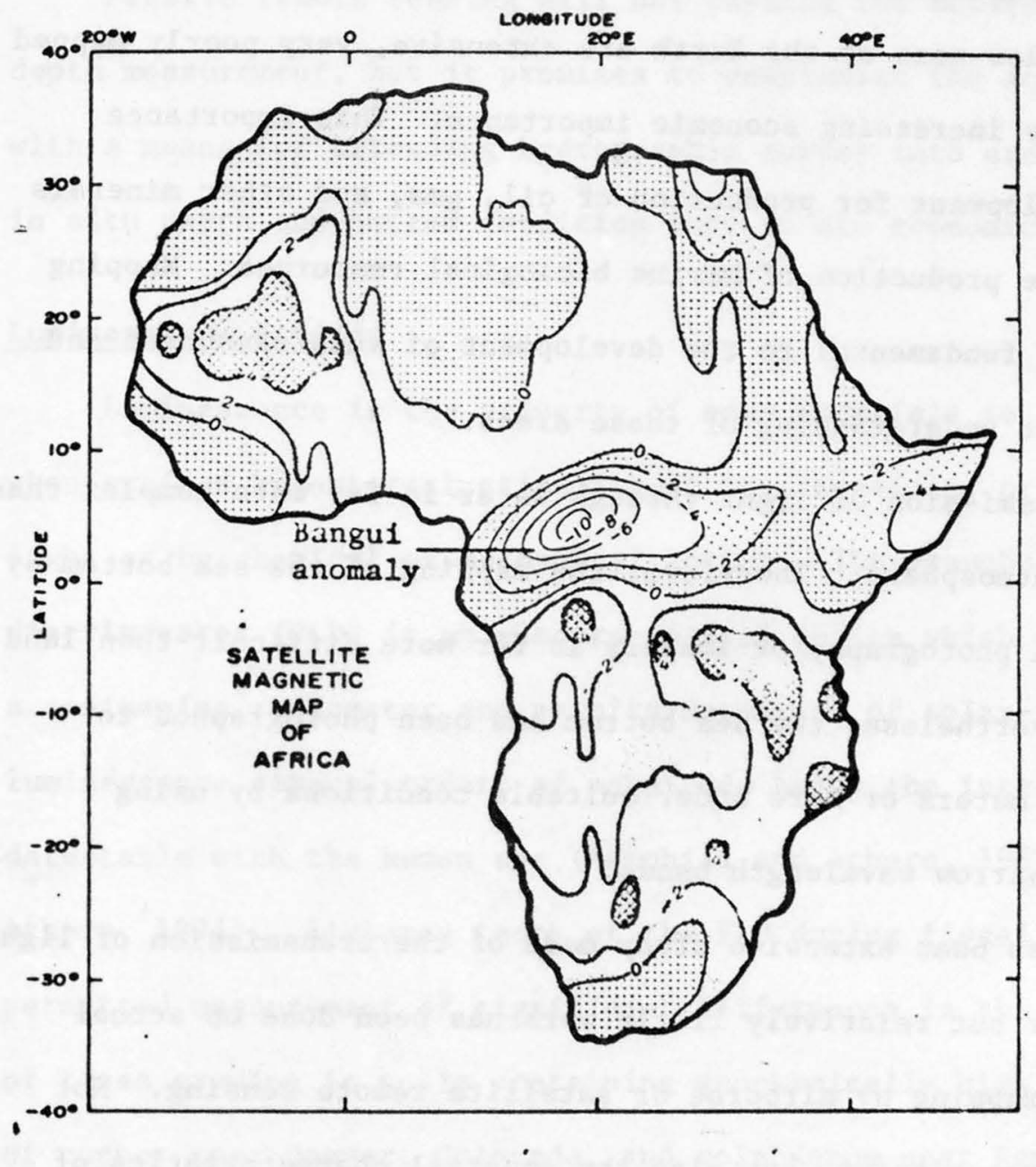

Fig. 18 - Satellite magnetic anomaly map of Africa. Contour interval is 2 gammas. 
coverage required for improved geomagnetic reference field models and charts.

\section{Shallow Seas Mapping by Passive Remote Sensing}

The shallow seas of the Earth are extensive, very poorly mapped and of rapidly increasing economic importance. This importance includes development for production of oil, gas, and other minerals as well as the production of marine biological resources. Mapping such areas is fundamental to the development of such resources and to man's basic understanding of these areas.

The transmission of light through water is far more complex than through the atmosphere. Therefore, the mapping of the sea bottom by multispectral photography or imagery is far more difficult than land mapping. Nevertheless, the sea bottom has been photographed to depths of 30 meters or more under suitable conditions by using appropriate narrow wavelength bands.

There has been extensive study made of the transmission of light through water but relatively little work has been done on actual shallow sea mapping by airborne or satellite remote sensing. Not only water transmission, but also the spectral characteristics of the sea bottom itself are involved, as well as a host of related problems such as illumination conditions, sea state, and atmospheric conditions. Satellites such as LANDSAT and Nimbus-G provide a unique and powerful tool for such application. 
By applying existing knowledge and by conducting additional experiments in some of the few well-mapped shallow sea areas, the potential for shallow sea mapping by passive means can be developed.

Passive remote sensing will not replace the active system of depth measurement, but it promises to complement the active systems with a means for extending hydrographic survey into areas where in situ depth and bottom condition surveys are economically impossible.

\section{$\underline{\text { Luminescence Studies }}$}

Luminescence is the property of some materials to emit light when excited by external stimuli such as ultraviolet or visible light or by chemical or mechanical action. The Fraunhofer line discriminator (FLD) is an electro-optical device which operates as a nonimaging radiometer and permits detection of solar-stimulated luminescence several orders of magnitude below the intensity detectable with the human eye (Hemphi11 and others, 1969; Watson and others, 1974). Airborne tests of the FLD during fiscal year 75 permitted measurement of significant differences in the luminescence of trees growing in soils containing geochemically high concentrations of copper near Denver, Colorado, and molybdenum near Reno, Nevada, from trees growing in background areas nearby. Figure 19 shows the diurnal variation of luminescence intensity of Pinus ponderosa in the test area near Denver. Other data collected from this test area at 3- to 5-week intervals over a 2-year period also show seasonal variation in luminescence intensity. In other airborne tests, the 
February 25, 1975

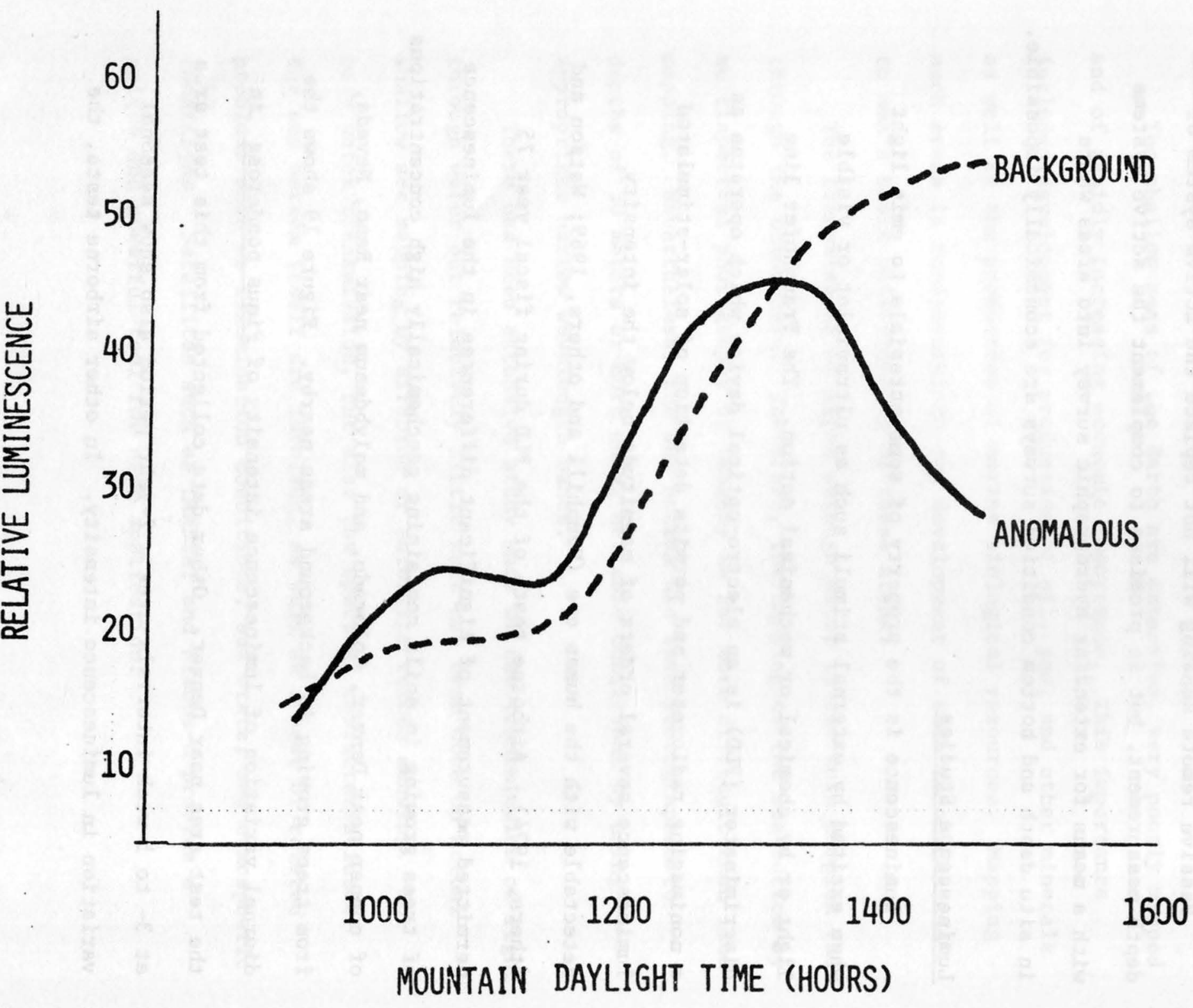

Fig. 19 - Curves showing diurnal variation in the luminescence intensity of pinus ponderosa growing in soils containing geochemically anomalous concentrations of copper, and in nearby background areas where concentrations are normal. 
FLD discriminated luminescing phosphate rock from gypsum and barren sandstone in southern California, dispersal of oil from a natural seep in the Santa Barbara Channel, cattle feed lot effluents near Denver, and paper mill and phosphate processing effluents in eastern and central Florida. Future work will be aimed at determining the feasibility of developing a luminescence imaging system, and in assessing its operational utility from aircraft and/or spacecraft.

Future work should also include an assessment of the use of pulsed lasers to stimulate phosphorescence decay time in the nanosecond and microsecond range. Preliminary work to define parameters of this research effort was conducted by Hemphill (1968), and positive results were obtained in the laboratory in discriminating plagioclase feldspars, calcite from dolomite, and mineral and fish oi1. Recent1y, Measures and others (1974) have shown that where fluorescence spectra of five refined and crude mineral oils are similarly shaped, broadband, and peaked within $200 \mathrm{~mm}$, differences in phosphorescence decay time between the same materials ranges from 2.5 to 8 nanoseconds.

\section{Satellite Thermography}

One particular area of satellite remote sensing technology, high-resolution satellite thermography (thermal infrared imagery), shows considerable promise in the scientific disciplines of geology, hydrology, soil science, and oceanography. The most advanced spacecraft whose data are generally available is the NOAA series of 
satellites. A very high resolution thermal infrared and visible sensor, called a VHRR, can acquire imagery of the same area on a 12-hour cycle (one day, one night image) at a ground resolution of about $900 \mathrm{~m}$ (about 0.5 nautical miles) with a temperature sensitivity of $0.5^{\circ} \mathrm{C}$ to $1^{\circ} \mathrm{C}$. Initial research by NOAA National Environmental Satellite Service (NESS) has shown this imagery to have high value in snow and sea ice mapping (figs. 20 and 21) and in hydrologic studies of the Great Lakes.

A thermal sensor, one band in the multispectral scanner (MSS) on LANDSAT-C, will have a three-fold improvement in spatial resolution (about $300 \mathrm{~m}$ to $400 \mathrm{~m}$ ) and about the same temperature sensitivity. This high-resolution thermography of the Earth's surface is expected to markedly increase our knowledge of the dynamic surface thermal properties of our planet, and to be of great significance to the geological, hydrologica1, oceanographic, and meteorological sciences. About the same time as LANDSAT-C thermal data are expected to be available, NASA plans to orbit the first of its Applications Explorer Mission (AEM-A) satellites, one devoted to thermal sensing of limited areas of the Earth's surface (NASA, 1975). The spatial resolution and thermal sensitivity of this satellite, called the Heat Capacity Mapping Mission (HCMM) lies between the capabilities of NOAA satellites and LANDSAT-C.

The diurnal and annual variation of surface temperature is perhaps the most dynamic characteristic of our planet's surface. The NOAA satellite series and other advanced satellites planned for 


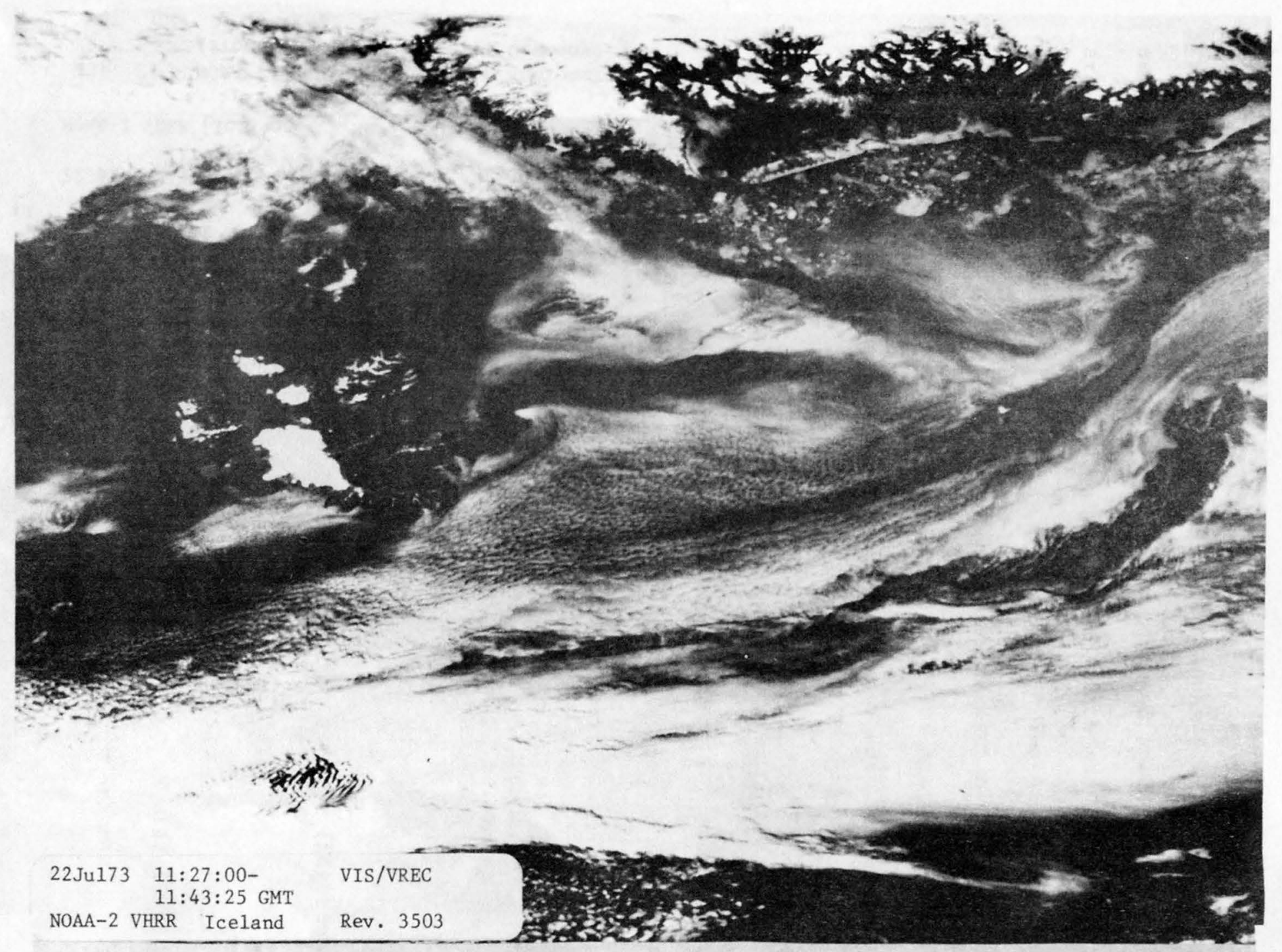

Fig. 20 - NOAA Very High Resolution Radiometer (VHRR) image (visible light) of Iceland and Greenland (from Bochum Observatory, Germany). 


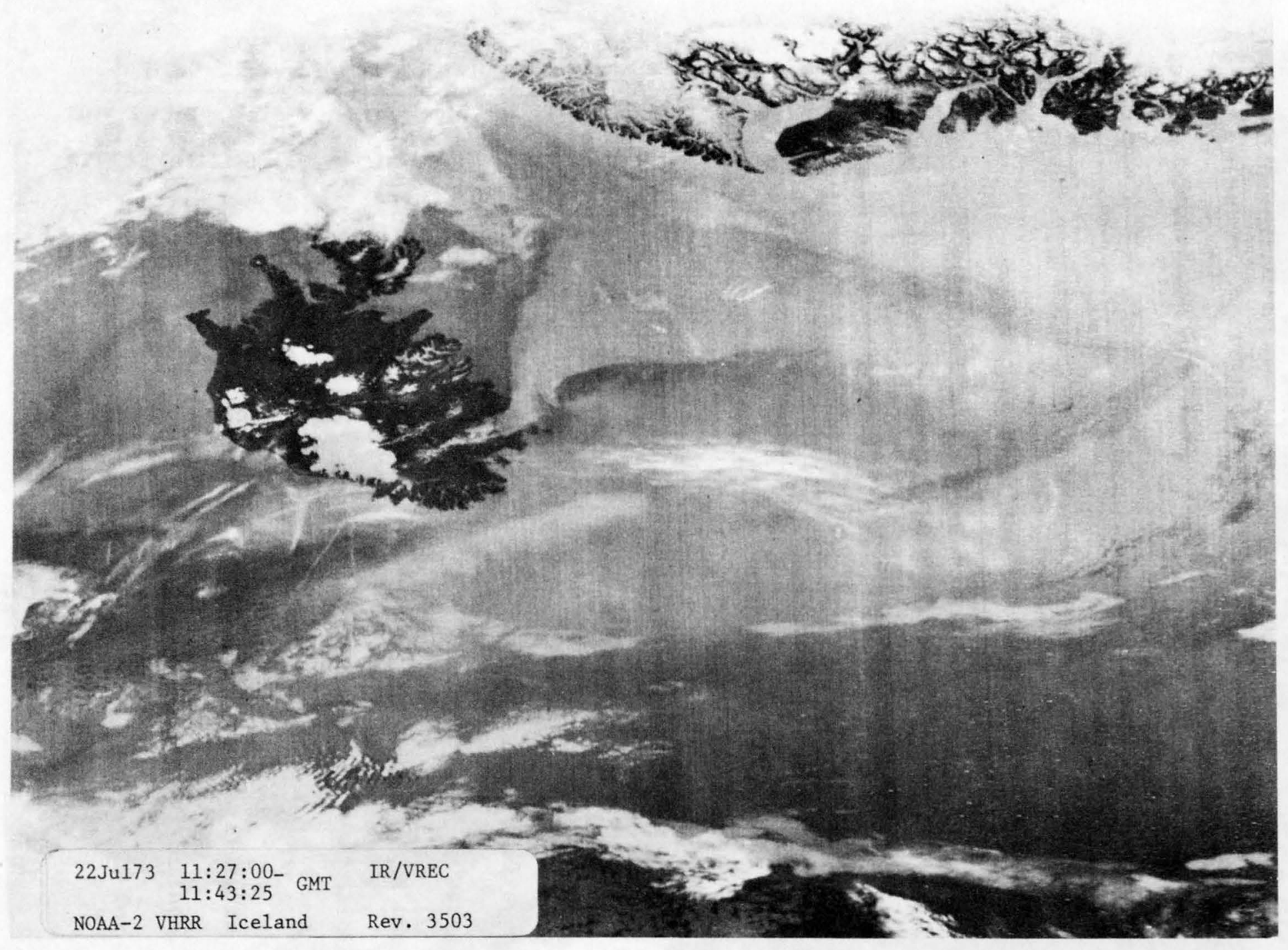

Fig. 21 - NOAA Very High Resolution Radiometer (VHRR) image (infrared) of Iceland and Greenland (from Bochum Observatory, Germany). 
launch in the next few years offer opportunities to those who wish to perform the scientific research necessary to convert this new data into useful knowledge.

\section{Microwave Studies of Natural Materials}

Microwave systems operate in radio wavelengths of from $1 \mathrm{~mm}$ to several metres. The basic systems can be divided into those which are passive and record energy emitted by the Earth and those which are active and record the reflection of energy. The active systems can produce images (conventional radar) or information in terms of scattering coefficients. Both the passive and the active systems provide an essentially all-weather capability and both address the objective of observing conditions both at and below the surface of the Earth. The spatial resolution of the systems are inversely proportional to the wavelengths while the penetration of the Earth is directly proportional to wavelengths: local conditions such as soil moisture, vegetative cover, and rock type have an effect on penetration.

The principal objectives of passive microwave radiometry experiments are:

a. Mapping the distribution of sea ice,

b. Mapping the distribution of oil slicks on water (Edgerton and Woolever, 1974),

c. Measurement of ice thickness (Adey, 1972),

d. Measuring soil moisture content (Newton and others, 1974), and

e. Surveys of potential geothermal areas. 
Several passive microwave radiometers have performed successfully from space platforms. For example a $19.3 \mathrm{GHz}$ (1.55 cm) scanner is installed on the Nimbus satellite together with a microwave spectrometer viewing the Earth at wavelengths of $1.4,0.96,0.56$, 0.55, and $0.51 \mathrm{~cm}$ (Gloersen and others, $1973 \mathrm{a}$ and b). The U.S.S.R. satellite, Cosmos 243, is equipped to measure radiation at four wavelengths between 0.8 and $8.5 \mathrm{~cm}$ (Basharinov and others, 1974). NASA has undertaken airborne collection of passive microwave data to advance knowledge of application particularly in the field of sea ice (Gloersen and others, 1973a and b) as has the U.S.S.R. The principal objectives of active microwave or radar surveys are:

a. Map the distribution of sea ice and thickness (Parashar and others, 1974),

b. Map the distribution of oil slicks (Kotlarski and Anderson, 1974),

c. Map sea state,

d. Produce "all weather" images of the Earth for geologic and other purposes,

e. To measure the water content of snow, and

f. To measure soil moisture (Rouse and others, 1974).

Radar systems have been used to collect three-dimensional data that can be converted into topographic information and to construct planimetric maps, but with limited precision (van Roessel and de Godoy, 1974). An opportunity to identify certain organic substances is suggested by the basic physics involved in the molecular rotational 
relationships that exist at these wavelengths but this opportunity remains to be explored.

Apo11o 17 carried a radar system and was designed to produce a subsurface profile of the lunar surface by operating at a series of wavelengths; Skylab carried a combined radar altimeter and scatterometer (a device to measure backscatter of the sea surface at a variety of angles) (Moore and others, 1974). Much research has been done with radar imagery to determine the signatures of various natural materials but much still remains to be done (Fischer, 1972). Nonetheless, the all-weather capability of the systems has led to operational use of the data for geologic and other purposes. The largest single radar survey (approximately 5 million $\mathrm{km}^{2}$ ) was undertaken by Brazil (Projecto RADAM, 1973). Numerous publications by scientists in the U.S.S.R. concern their use of radar data (Komarov and others, 1973). Plans are being advanced for imaging radars to operate from space as a part of the Shuttle Sortie missions in 1980. The European Space Research Organization has undertaken a feasibility study for a radar imaging system for use from space (Skenderoff and others, 1974). 
SUMMARY

During the past few years the primary emphasis in the EROS Program has been on preparing for the launch of LANDSAT, in developing methods for analysis of the data that have been obtained and in conducting studies that show the value of these data to the solution of resource and environmental problems. It has been necessary to put major effort into developing capabilities to provide data to users, and to transfer the knowledge of uses and methods of analysis to the users.

The increasing demand for data products is one indication of the success of the program. Each improvement in delivery time or data quality has been followed by an increase in demand for data products. Another indication of success is the number of requests for workshops and training in methods of using the data. The real measure of success is in the value of the data to resource management, environmental protection, and scientific research. This is a difficult measure to quantify. A number of important examples have been summarized in this paper. The scientific and technical capability has been demonstrated in many cases.

The next major objective of the EROS Program must be to include LANDSAT capabilities in the continuing programs of the various resource agencies. There is an increasing degree of interest in applying the data to such programs on a limited, demonstration basis. 
Agencies with operational responsibilities express three reasons for caution in becoming dependent on LANDSAT data. These are:

a. LANDSAT is experimental. There is no assurance of continuity beyond about 1980 , or even earlier if a spacecraft or launch vehicle fails.

b. Data are not available scon enough to be used in making time-critical decisions.

c. Standard photographic products contain less than the complete data content of the original digital data, thus precluding their use in some unique applications.

The last two of these reasons are technical. The solutions are known and, within the resources available, NASA and the EROS Program are augmenting their data processing and distribution systems to make the necessary improvements. The first deficiency relates to policy and the intention of the United States to continue in a leadership role in global Earth resources satellite programs.

A number of research programs have demonstrated that space technology can provide unique measurement capabilities for the future. The examples of precision distance measurements over large distances, global magnetic surveys, mapping heat capacity of the Earth's surface, observation of bottom features of shallow seas, a11-weather capabilities using active and passive microwave, and measurement of types of energy such as luminescence are examples that are discussed in this paper. This list is not exhaustive, but the potential for these capabilities to add to our knowledge of the Earth is great. 
Appropriate data systems to provide adequate distribution and some specialized products must be considered with each of these capabilities if the full benefits are to be realized.

An important factor, that is often overlooked, is becoming more and more apparent from our experience with the LANDSAT program. This factor is the unifying influence of a global data base with uniform characteristics that serves scientists in many disciplines. The results are threefold: 1) scientists in different disciplines are communicating better and understanding the relations of their disciplines to other Earth sciences; 2) international scientific communication has been improved, because scientists from all nations can obtain data of uniform characteristics and compare their results of analysis and analysis methods. The number of international applications examples using LANDSAT data that are discussed in this paper illustrates the importance of this international communication; and 3 ) the availability of repetitive data of dynamic phenomena permits the establishment of wholly new types of scientific studies, many of enormous potential value to our understanding of the global environment. 


\section{REFERENCES}

Adey, A. W., 1972, Microwave radiometry for remote sensing from aircraft and spacecraft, in Resource Satellites and Remote Airborne Sensing for Canada: Ottawa, Canada, The Dept. of Energy, Mines and Resources, p. 613-626.

Albert, N. R. D., 1975, Interpretation of Earth Resources Technology Satellite Imagery of the Nabesna Quadrangle, Alaska: U. S. Geol. Survey, Misc. Field Studies Map MF655J, 2 sheets, scale 1:250,000.

Batson, R. M., and Eliason, E. M., 1975, Stereoscopic ERTS pictures [abs.]: Am. Soc. Photogramm., Fall Tech. Mtg. Phoenix 1975, Program, (in press).

Basharinov, A. E., Borodin, L. F., and Shutko, A. M., 1974, Passive microwave sensing of moist soils: Internat. Symposium on Remote Sensing of Environment, 9th, Ann Arbor, Mich. 1974 Proc., p. $363-367$.

Blinn, J. C., III, Cone1, J. E., and Quade, J. G., 1972, Microwave emission for geologic materials: Observations of interference effects: Jour. Geophys. Research, v. 27, no. 23, p. 4366-4378.

Carter, Virginia, 1975, The Great Dismal Swamp of Virginia and North Carolina, in ERTS-1: A new window on our planet: U. S. Geol. Survey Prof. Paper 929, p. 316-320 (in press). 
Carter, W. D., 1974, Tectolinear interpretation of an ERTS-1 mosaic, La Paz area, southwest Bolivia, southeast Peru and northern Chile: Committee on Space Research, 17th Plenary Mtg., Workshop for Developing Nations, Sao Jose dos Campos, Brazil 1974, Paper B. 4.3 .

Carter, W. D., 1975, Structural geology and mineral resources inventory of the Andes Mountains, S. A., in ERTS-1: A new window on our planet: U. S. Geol. Survey Prof. Paper 929, p. 92-98 (in press).

Coker, A. E., Higer, A. L., Sauer, S., and Rogers, R. H., 1975, Remotely-sensed data used to delineate land-water cover in coal mining regions in eastern Tennessee [abs.]: NASA L. B. Johnson Space Center, Earth Resources Survey Symposium, Houston, Tex. 1975, Abs. Paper E-8, p. 84.

Coker, A. E., Higer, A. L., Rogers, R. H., Shah, N. J., Reed, L., and Walker, S., 1975, Automatic categorization of land-water cover types of the Green Swamp, Florida, using Skylab multispectral scanner $(\mathrm{S}-192)$ data [abs.]: NASA L. B. Johnson Space Center, Earth Resources Survey Symposium, Houston, Tex. 1975, Abs., Paper E-15, p. 97.

Colvocoresses, A. P., 1975, Operational applications of ERTS [LANDSAT] to map revision: U. S. Geol. Survey Memo. for the Record (EC-25-ERTS), $3 \mathrm{p}$. 
Deutsch, Morris, and Ruggles, F. R., 1974, Optical data processing and projected applications of the ERTS-1 imagery covering the 1973 Mississippi valley floods: Water Resources Bul1., v. 10, no. 5, p. 1023-1039,

Deutsch, Morris, Ruggles, F. R., and Rabchevsky, George, 1974 , Flood applications of the Earth Resources Technology Satellite: IEEE Earth Environment and Resources Conf., Phila., Pa., 1974, Digest of Tech. Papers, v. 1, p. 22-23.

Edgerton, A. T., and Woolever, G., 1974, Airborne oil pollution surveillance system [abs.]: Internat. Symposium on Remote Sensing of Environment, 9th, Ann Arbor, Mich. 1974, Proc., p. 1791 .

Fischer, W. A., 1972, Status of remote sensing: Internat. Soc. Photogramm., Cong., 12th, Ottawa, Canada 1972, 48 p., mimeo.

Fischer, W. A., and Lathram, E. H., 1973, Concealed structures in Arctic Alaska identified on ERTS-1 imagery: $0 i 1$ and Gas Jour., v. 71 , p. 97-102.

Gloersen, P., Wilheit, T. T., Chang, T. C., Nordberg, W., and Campbe11, W. J., 1973a, Microwave maps of the polar ice of the Earth: NASA Goddard Space F1ight Center, X-65-2-73-269. 
Gloersen, P., Nordberg, W., Schmugge, T. J., Wilheit, T. T., and Campbe11, W. J., 1973b, Microwave signatures of first-year and multiyear sea ice: Jour. Geophys. Research, v. 28, no. 18 , p. $3564-3572$.

Gower, J. F. R., 1974, Measurement of sea surface currents using airborne doppler radar and inertial navigation systems: Internat. Symposium on Remote Sensing of Environment, 9th, Ann Arbor, Mich. 1974, Proc., p. 1657-1667.

Hemphill, W. R., 1968, Application of ultraviolet reflectance and stimulated luminescence to the remote detection of natural materials: U. S. Geol. Survey open-file report, 36 p., 15 illus.

Hemphill, W. R., Stoertz, G. E., Markle, D. A., 1969, Remote sensing of luminescent materials: Internat. Symposium on Remote Sensing of Environment, 6th, Ann Arbor, Mich. 1969, Proc., p. 565-585.

Komarov, V. B., Starostin, V. A., Nyavro, B. P., 1973, Radiolokatsionnaya Aeros yemka $i$ yeye znacheniye $v$ komplekse aero-i kosmicheskikh metodov geologicheskikh issledovaniy (Radar aerial survey and its significance in the complement of aerial and space geological research techniques): USSR Academy of Sciences IKI Inst.; Moscow, $23 \mathrm{p}$. 
Kotlarski, J. R., and Anderson, H. R., 1974, Oil slick detection by X-band synthetic aperture radar: Internat. Symposium on Remote Sensing of Environment, 9th, Ann Arbor, Mich. 1974, Proc., p. $1775-1790$.

Lathram, E. H., 1973, Analysis of state of vehicular scars on Arctic tundra, Alaska: NASA Goddard Space Flight Center, Symposium on Significant Results Obtained from ERTS-1, Wash., D. C., Dec., Proc., v. A, p. 633-641 NASA SP-351.

MacDonald, W. R., 1975a, Antarctic cartography, in ERTS-1: A new window on our planet: U. S. Geol. Survey Prof. Paper 929, p. $37-42$ (in press).

MacDonald, W. R., 1975b, Glaciology in Antarctica, in ERTS-1: A new window on our planet: U. S. Geol. Survey Prof. Paper 929, p. 194-195 (in press).

McQuillan, A. K., and Clough, D. J., 1973, Benefits of remote sensing of sea ice: The Dept. of Mines, and Resources; Canada Centre for Remote sensing, Research Rept. 73-3.

Measures, R. M., Houston, W. R., and Stephenson, D. G., 1974, Laser induced fluorescence decay spectra - a new form of environmental signature: Optical Eng., v. 13, no. 6. 
Miller, J. B., 1975, ERTS image studies as applied to petroleum exploration in Kenya: Univ. Kansas Conf. on Remote Sensing, Lawrence, 1975, Abs. of Papers, p. 34-40.

Moore, G. K., and North, G. W., 1974, Flood inundation in the southeastern United States from aircraft and satellite imagery: Water Resources Bulletin, v. 10, no. 5, p. 1082-1096.

Moore, R. K., Claassen, J. P., Cook, A. C., Fayman, D. L., Holtzman, J. C., Sobti, A., Spencer, W. E., Ulaby, F. T., Young, J. D., Pierson, W. J., Cardone, V. J., Hayes, J., Spring, W., Kern, R. J., and Hatcher, N. M., 1974, Simultaneous active and passive microwave response of the Earth-The Skylab Radscat Experiment: Internat. Symposium on Remote Sensing of Environment, 9th, Ann Arbor, Mich. 1974, Proc., p. 189-217.

National Aeronautics and Space Administration, 1975, Data use investigations for Applications Explorer Mission - A (Heat Capacity Mapping Mission): NASA, Announcement of Opportunity, A. 0 . No. $0 A-75-2,8$ p.

Newton, R. W., Lee, S. L., Rouse, J. W., Jr., and Paris, J. F., 1974, On the feasibility of remote monitoring of soil moisture with microwave sensors: Internat. Symposium on Remote Sensing of Environment, 9th, Ann Arbor, Mich. 1974, Proc., p. 725-738. 
Parashar, S. K., Bigg, A. W., Fung, A. K., and Moore, R. K., 1974, Investigation of radar discrimination of sea ice: Internat. Symposium on Remote Sensing of Environment, 9th, Ann Arbor, Mich. 1974, Proc., p. 323-332.

Projecto RADAM, 1973, Levantamento de recursos naturais geologia, geomorfologia, solos, vegetaco, uso potential da terra: Rio de Janiero, Brasil, Ministerio das Minas e Energia, Departamento Nacional de Producão Mineral, v. 1, 2, and 3.

Rango, A. and Anderson, A. T., 1974, Flood hazard studies in the Mississippi River basin using remote sensing: Water Resources Bulletin, v. 10, no. 5, p. 1060-1081.

Regan, R. C., Cain, J. C., and Davis, W. M., 1975, A global magnetic anomaly map: Jour. Geophys. Research, v. 80, no. 5, p. 794-802.

Richter, D. H., Albert, N. R. D., Barnes, D. F., Griscom, A., Marsh, S. P. and Singer, D. A., 1975, The Alaskan Mineral Resource Assessment Program: Background information to accompany folio of geologic and mineral resource maps of the Nabesna Quadrangle, Alaska: U. S. Geol. Survey Circ. 718, $11 \mathrm{p}$.

Robinove, C. J., 1975, Disaster assessment and warning with LANDSATs [abs.]: Internat. Symposium on Remote Sensing of Environment, 10th, Ann Arbor, Mich. 1975, summaries (in press). 
Rowan, L. C., Wetlaufer, P. H., Goetz, A. F. H., Billingsley, F. C., and Stewart, J. H., 1974, Discrimination of rock types and detection of hydrothermally altered areas in south-central Nevada by the use of computer-enhanced ERTS images: U. S . Geol. Survey Prof. Paper 883, 35 p.

Ruggles, F. H., written communication.

Schmidt, R. G., 1975, Detection of hydrothermal sulfide deposits, Saindak area, Western Pakistan, in ERTS-1: A new window on our planet: U. S. Geol. Survey Prof. Paper 929, p. 89-91 (in press).

Skenderoff, C., Guignard, J. P., Coldrick, J. R., Mooney, H., and Noel, J. , 1974, A preliminary feasibility study on a synthetic aperture radar (SARSAT) for earth resources surveys: Internat. Symposium on Remote Sensing of Environment, 9th, Ann Arbor, Mich. 1974, Proc., p. 1517-1540.

State of Arizona, 1975, ARIS Cooperative Publication No. 5; Set of 5 climatology map sheets using the LANDSAT image map of Arizona as a base, Ariz. Resources Info. System.

Thorarinsson, Sigurdur, Sæmundsson, Kristjan, and Williams, R. S., Jr., 1973 [1974], ERTS-1 image of Vatnajökull: Analysis cf glaciological, structural, and volcanic features: Jökull, v. 23, p. 7-17. 
U. S. Geo1. Survey, 1965, Scope, importance and resolution requirements of geoscience problems to be attacked by orbital remote-sensor measurements: U. S. Geol. Survey open-file report, 85 p.

van Roesse1, J. W., and de Godoy, R. C., 1974, SLAR mosaics for Project RADAM: Photogramm. Eng., v. 40, no. 5, p. 583-595.

Ward, P. L., Endo, E. T., Harlow, D. H., Allen, R., Marquez, D., and Eaton, J. P., 1974, Development and evaluation of a prototype global volcano surveillance system utilizing the ERTS-1 satellite data collection system: U. S. Geol. Survey open-file report, 154 p; also available as NASA-CR-139222, 168 p. and from NTIS, E74-10689.

Watkins, Allen H., 1975, The role of the EROS Data Center within the earth resources program [abs.]: NASA L. B. Johnson Space Center, Earth Resources Survey Symposium, Houston, Tex. 1975, Abs. Paper U-2, p. 41-42.

Watson, R. D., Hemphill, W. R., Hessin, T. D., and Bigelow, R. C., 1974, Prediction of the Fraunhofer 1ine detectivity of luminescent materials: Internat. Symposium on Remote Sensing of Environment, 9th, Ann Arbor, Mich. 1974, Proc., p. 1959-1980.

Weisnet, D. R., McGinnis, D. F., and Pritschard, J. A., 1974, Mississippi River floods by the NOAA-2 satellite: Water Resources Bulletin, v. 10, no. 5, p. 1040-1049. 
Williams, R. S., Jr., and Thorarinsson, Sigurður, 1973

[1974], ERTS-1 image of Vatnajökull area: Jökull, v. $23, \mathrm{p} \cdot 1-6$.

Williams, R. S., Jr.; Böðvarsson, Agúst; Friðriksson, Sturla; Pálmason, Guðmundur; Rist, Sigurjón;

Sigtryggsson, Hlynur; Sæmundsson, Kristján; Thorarinsson, Sigurður; and Thorsteinsson, Ingvi, 1974, Environmental studies of Iceland with ERTS-I imagery; Internat. Symposium on Remote Sensing of Environment, 9th, Ann Arbor, Mich. 1974, Proc., v. 1, p. 31-81.

Williams, R. S., Jr., and Carter, W. D., eds., 1975, ERTS-1, A new window on our planet: U. S. Geol. Survey Prof. Paper 929, 400 p., 250 illus. (in press).

Williamson, A. N., 1974, Mississippi flood maps from ERTS-1 data: Water Resources Bulletin, v. 10, no. 5, p. 1050-1059.

Wray, J. R., 1975, Three U. S. urban areas analyzed from aircraft, LANDSAT, and Skylab sensors [abs.]: NASA L. B. Johnson Space Center, Earth Resources Survey Symposium, Houston, Tex. 1975, Abs., Paper L-12, p. 224-225. 
